\title{
Transcatheter treatment for tricuspid valve disease
}

\author{
Fabien Praz ${ }^{1 *}$, MD; Denisa Muraru², MD; Felix Kreidel ${ }^{3}$, MD; Philipp Lurz ${ }^{4}$, MD; Rebecca T. Hahn ${ }^{5}$, MD; \\ Victoria Delgado 6 , MD; Michele Senni ${ }^{7}, \mathrm{MD}$; Ralph Stephan von Bardeleben ${ }^{3}$, MD; Georg Nickenig ${ }^{8}$, MD; \\ Jörg Hausleiter ${ }^{9}, \mathrm{MD}$; Antonio Mangieri ${ }^{10}$, MD; Jose L. Zamorano ${ }^{11}$, MD; Bernard Prendergast ${ }^{12}$, MD; \\ Francesco Maisano ${ }^{13}$, MD
}

\begin{abstract}
1. Bern University Hospital, University of Bern, Bern, Switzerland; 2. Department of Medicine and Surgery, University of Milano-Bicocca, Milan, and Istituto Auxologico Italiano, IRCCS, Department of Cardiological, Neural and Metabolic Sciences, San Luca Hospital, Milan, Italy; 3. Department of Cardiology, Heart Valve Center, University Medical Center Mainz, Mainz, Germany; 4. Department of Cardiology, Heart Center Leipzig at University of Leipzig, Leipzig, Germany; 5. Cardiology Department, NewYork-Presbyterian/Columbia University Medical Center, New York, NY, USA; 6. Department of Cardiology, Heart Lung Centre, Leiden University Medical Center, Leiden, the Netherlands; 7. Cardiology Division, Cardiovascular Department, Hospital Papa Giovanni XXIII, Bergamo, Italy; 8. Department of Internal Medicine II, Heart Center Bonn, University Hospital Bonn, Bonn, Germany; 9. Department of Cardiology, University Hospital, Ludwig-Maximilians-Universität München (LMU Munich), Munich, Germany; 10. Interventional Cardiology Unit, Maria Cecilia Hospital, GVM Care and Research, Cotignola, Italy; 11. Cardiology Department, University Hospital Ramón y Cajal, Madrid, and Instituto Ramón y Cajal de Investigación Sanitaria (IRYCIS), Madrid, Spain; 12. Department of Cardiology, St Thomas' Hospital and Cleveland Clinic, London, United Kingdom; 13. Department of Cardiothoracic Surgery, IRCCS Ospedale San Raffaele, Milan, Italy
\end{abstract}

A list of collaborators can be found in the Appendix paragraph.

This paper also includes supplementary data published online at: https://eurointervention.pcronline.com/doi/10.4244/EIJ-D-21-00695

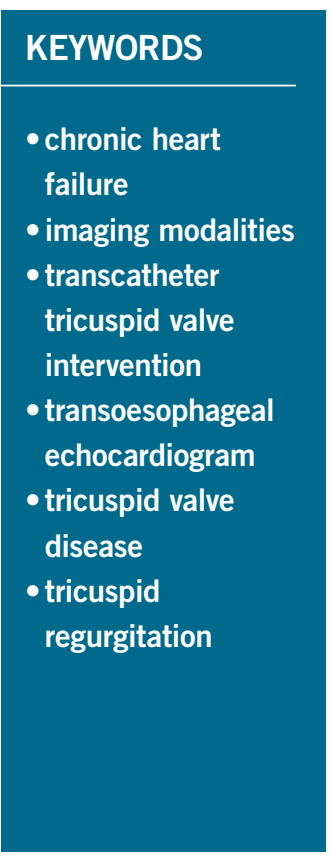

\begin{abstract}
Approximately $4 \%$ of subjects aged 75 years or more have clinically relevant tricuspid regurgitation (TR). Primary TR results from anatomical abnormality of the tricuspid valve apparatus and is observed in only $8-10 \%$ of the patients with tricuspid valve disease. Secondary TR is more common and arises as a result of annular dilation caused by right ventricular enlargement and dysfunction as a consequence of pulmonary hypertension, often caused by left-sided heart disease or atrial fibrillation. Irrespective of its aetiology, TR leads to volume overload and increased wall stress, both of which negatively contribute to detrimental remodelling and worsening TR. This vicious circle translates into impaired survival and increased heart failure symptoms in patients with and without reduced left ventricular ejection fraction. Interventions to correct TR are underutilised in daily clinical practice owing to increased surgical risk and late patient presentation. The recently introduced transcatheter tricuspid valve interventions aim to address this unmet need. Dedicated expertise and an interdisciplinary Heart Team evaluation are essential to integrate these new techniques successfully and select patients. The present article proposes a standardised approach to evaluate patients with TR who may be candidates for transcatheter interventions. In addition, a state-of-the-art review of the available transcatheter therapies, the main criteria for patient and device selection, and information concerning the remaining uncertainties are provided.
\end{abstract}

*Corresponding author: Department of Cardiology, Inselspital, University of Bern, Freiburgstrasse 15, CH-3010 Bern, Switzerland.E-mail: fabien.praz@insel.ch 


\section{Abbreviations}

2D

3D

$\mathrm{AF}$

CCT

CIED

CMR

EROA

HF

NOAC non-vitamin $\mathrm{K}$ antagonist oral anticoagulants

PHT pulmonary hypertension

SPAP systolic pulmonary artery pressure

STR secondary tricuspid regurgitation

TAPSE tricuspid annular plane systolic excursion

TEE transoesophageal echocardiography

TR tricuspid regurgitation

TTE transthoracic echocardiography

T-TEER tricuspid transcatheter edge-to-edge repair

TTVI transcatheter tricuspid valve intervention

TTVR transcatheter tricuspid valve replacement

TV tricuspid valve

\section{Introduction}

Tricuspid regurgitation (TR) is a common echocardiographic finding that is present in $70-90 \%$ of the general population ${ }^{1}$. While a trivial form is often seen in healthy individuals, moderate or severe TR has an age- and sex-adjusted prevalence of $0.55 \%$, with a higher incidence in women and a strong age dependency ${ }^{2}$ - approximately $4 \%$ of subjects aged 75 years or more have clinically relevant $\mathrm{TR}^{2}$.

The development and successful results of transcatheter aortic valve implantation, followed by transcatheter therapies for mitral valve disease have opened a myriad of opportunities for transcatheter treatment of TR, a valvular heart disease that has traditionally been considered benign and often left untreated.
Chronic severe TR leads to volume overload and increased wall stress of the right ventricle (RV), which negatively contribute to detrimental remodelling and worsening TR. This vicious circle translates into impaired survival and increased heart failure (HF) symptoms in patients with and without reduced left ventricular ejection fraction ${ }^{3-5}$. Therefore, there is an unmet clinical need that requires prompt action. However, there remain many uncertainties and inconsistencies such as a non-systematic approach to assessing tricuspid valve (TV) disease, confusing terminology on anatomy and aetiology, as well as challenges in determining the mechanism and severity of TR and its consequences on the right chambers.

The present article proposes a standardised approach to evaluate patients with TR who may be candidates for transcatheter interventions. In addition, a state-of-the-art review of the available transcatheter therapies, the main criteria for patient and device selection, and information concerning the remaining uncertainties are provided.

\section{ANATOMY OF THE TRICUSPID VALVE}

The TV is the largest and most anterior cardiac valve with complex and variable anatomy ${ }^{6}$. Although its name infers the presence of three well-defined leaflets, numerous anatomical variations exist $^{7,8}$. Differing terminology has been used ${ }^{6-8}$ and a simplified nomenclature is proposed (Figure 1$)^{9}$ that has been derived from the analysis of 579 patients with various TR severity from 4 centres experienced in the assessement and treatment of TV disease. Based on the images provided, TV morphology could be determined in all but 4 patients (99\%): $54 \%$ had type I, $4.5 \%$ had type II, $2.6 \%$ had type IIIA, 32.1\% had type IIIB, 3.8\% had type IIIC, and $2.4 \%$ had type IV. An in-depth understanding of the TV anatomy, in particular the number and location of supernumerary leaflets or scallops, is essential for procedural planning and may influence intervention outcome ${ }^{10}$.

Transoesophageal echocardiographic (TEE) imaging from the transgastric short-axis view (or three-dimensional [3D] volume-

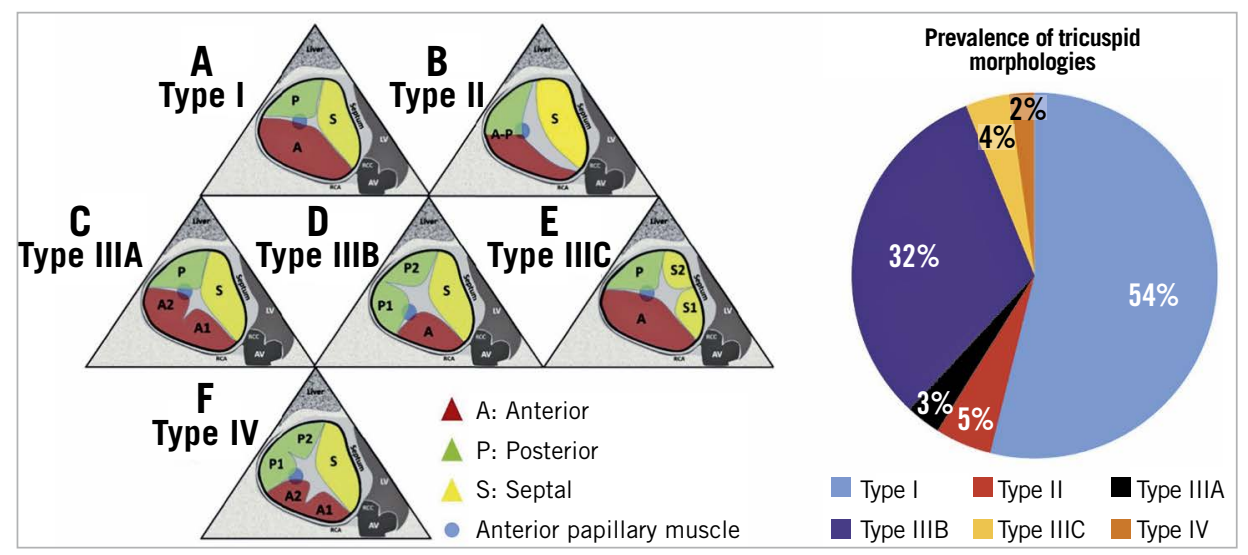

Figure 1. Proposed nomenclature for tricuspid valve classification. Left panel. Proposed nomenclature for tricuspid valve classification scheme (anterior papillary muscle [blue circle] defines separation of anterior and posterior leaflets). A) Type I: 3-leaflet configuration. B) Type II: 2-leaflet configuration. C) - E) Type III: 4-leaflet configurations. F) Type IV: 5-leaflet configuration. Right panel. Incidence of each morphology. A: anterior leaflet; AV: aortic valve; P: posterior leaflet; $S$ : septal leaflet. Adapted from Hahn et al ${ }^{9}$, with permission. 
rendered equivalent) enables delineation of TV morphology. Steps to identify the leaflets are illustrated in Supplementary Figure 1.

\section{CLASSIFICATION OF TRICUSPID REGURGITATION}

Characterisation of the main morphologic and/or functional abnormalities resulting in TR is an essential aspect of transcatheter TV device selection. Primary TR results from anatomical abnormality of the TV apparatus and is observed in only $8-10 \%$ of patients with TV disease. Secondary TR (STR) is more common and arises as a result of annular dilation caused by RV enlargement and dysfunction due to pressure/volume overload as a consequence of pulmonary hypertension (PHT), often caused by left-sided heart disease, or atrial fibrillation (AF) with normal RV pressures (atrial/ atriogenic or isolated TR). STR may also develop after left-sided valve surgery, probably due to silent ischaemic RV damage ${ }^{11,12}$. Implantation of cardiac implantable electronic device (CIED) RV leads provokes relevant TR in $20-30 \%$ of patients ${ }^{13-15}$, which frequently progresses over time ${ }^{16}$.

Carpentier's functional classification of leaflet mobility was intended to guide mitral valve surgical repair or replacement and its application to the TV is less well established ${ }^{17}$. In addition to differences in TV leaflet mobility, patients with STR also demonstrate variable remodelling of the TV annulus, right atrium (RA) and RV secondary to the underlying pathology ${ }^{18}$. Definition of different TR groups is prognostically important since disease aetiology determines long-term outcomes. Accordingly, we propose a novel integrative classification of TR (Table 1) that accounts for the pathophysiology, imaging characteristics, clinical management and outcome, while recognising that differentiation of the initial aetiology based on valve and chamber morphology/function may be challenging as TV disease progresses.

Table 1. Proposed new integrated classification of TR.

\begin{tabular}{|c|c|c|c|c|}
\hline & $\begin{array}{l}\text { Leaflet } \\
\text { structure }\end{array}$ & Pathophysiology & Aetiology & Imaging \\
\hline \multicolumn{5}{|c|}{ Secondary (functional) } \\
\hline A. Atrial & Normal & $\begin{array}{l}\text { RA enlargement and } \\
\text { dysfunction leading to } \\
\text { significant isolated annular } \\
\text { dilation; RV often normal* }\end{array}$ & $\begin{array}{l}\text { Carpentier I: } \\
\text { Atrial fibrillation/flutter }{ }^{101} \\
\text { Age }^{102} \\
\text { Heart failure with } \\
\text { preserved ejection } \\
\text { fraction } \\
{ }^{103,104}\end{array}$ & $\begin{array}{l}\text { Marked TV annular dilation is the dominant } \\
\text { mechanism } \\
\text { TV leaflet tethering is absent or minimal (except } \\
\text { for late stages with secondary RV dysfunction) } \\
\text { TV leaflet mobility is typically normal (Carpentier } \\
\text { type I) } \\
\text { RA is significantly dilated } \\
\text { RV volume is typically normal (except in late } \\
\text { stages) }\end{array}$ \\
\hline B. Ventricular & Normal & $\begin{array}{l}\text { RV enlargement and/or } \\
\text { dysfunction leading to } \\
\text { significant leaflet tethering } \\
\text { and annular dilation }\end{array}$ & $\begin{array}{l}\text { Carpentier IIIB: } \\
\text { Left-sided ventricular or } \\
\text { valve disease }{ }^{11,12} \\
\text { Pulmonary hypertension }{ }^{102} \\
\text { RV cardiomyopathy } \\
\text { RV infarction }\end{array}$ & $\begin{array}{l}\text { Marked TV leaflet tethering is the dominant } \\
\text { mechanism } \\
\text { TV leaflet mobility is typically restricted in systole } \\
\text { (Carpentier type IIIB) } \\
\text { TV annulus, RV and RA are dilated and/or } \\
\text { dysfunctional }\end{array}$ \\
\hline CIED-related & $\begin{array}{l}\text { Normal/ } \\
\text { abnormal }\end{array}$ & $\begin{array}{l}\text { Leaflet impingement } \\
\text { Leaflet/chordal entanglement/ } \\
\text { chordal rupture } \\
\text { Leaflet adherence } \\
\text { Leaflet laceration/perforation } \\
\text { Leaflet avulsion (following } \\
\text { lead extraction) }\end{array}$ & $\begin{array}{l}\text { Pacemaker } \\
\text { Implantable cardiac } \\
\text { defibrillator (ICD) } \\
\text { Cardiac resynchronisation } \\
\text { therapy (CRT) } \\
\text { devices }^{105-108}\end{array}$ & $\begin{array}{l}\text { TV leaflet structural abnormalities may be present } \\
\text { TV leaflet mobility is variable (all Carpentier } \\
\text { types) } \\
\text { TV annulus, RV and RA are typically dilated } \\
\text { (except for acute TR) }\end{array}$ \\
\hline Primary (organic) & Abnormal & $\begin{array}{l}\text { Lack of leaflet coaptation due } \\
\text { to intrinsic changes leading } \\
\text { to restricted or excessive } \\
\text { leaflet mobility or leaflet } \\
\text { perforation }\end{array}$ & $\begin{array}{l}\text { Carpentier I: } \\
\text { Congenital } \\
\text { Endocarditis } \\
\text { Carpentier II: } \\
\text { Myxomatous disease } \\
\text { Traumatic } \\
\text { Post biopsy } \\
\text { Carpentier IIIA: } \\
\text { Carcinoid }{ }^{109} \\
\text { Rheumatic } \\
\text { Radiotherapy } \\
\text { Tumours }\end{array}$ & $\begin{array}{l}\text { TV leaflet structural abnormalities characteristic of } \\
\text { each primary aetiology are the dominant } \\
\text { mechanisms } \\
\text { TV leaflet mobility is variable (all Carpentier } \\
\text { types) } \\
\text { TV annulus, RV and RA are typically dilated } \\
\text { (except in acute TR) }\end{array}$ \\
\hline
\end{tabular}




\section{DEFINITION OF DISEASE SEVERITY}

The functional anatomy of the TV apparatus can be evaluated by 3D transthoracic echocardiography (3D-TTE) and/or 3D-TEE, and severity of TR assessed using semi-quantative parameters of colour and spectral Doppler (Supplementary Figure 2) ${ }^{19}$. Additional advanced imaging may be of value when echocardiography is either of insufficient quality or inconclusive (Table 2). Specific signs of severe TR include wide systolic leaflet separation, hepatic vein systolic flow reversal demonstrated by pulsed-wave Doppler, and a triangular (early peaking) continuous-wave Doppler TR signal. RV and RA dilatation are supportive signs. The TR colour jet is not a measure of regurgitant volume, but is determined by jet momentum. Thus, whilst a small colour TR jet may reliably reflect trivial or mild TR and a very large jet is specific to severe TR, patients with PHT may demonstrate larger jets that overestimate TR orifice area. Furthermore, rapid equalisation of RA and RV pressures in severe TR may be associated with non-aliasing jets.

Quantitative measures of TR are therefore essential to define severity, including estimation of anatomical regurgitant orifice area by vena contracta measurement and quantification of physiological effective regurgitant orifice area (EROA) and regurgitant volume (RVol). A vena contracta $\geq 7 \mathrm{~mm}$ generally indicates severe $\mathrm{TR}^{19,20}$, although some studies suggest a threshold of $9 \mathrm{~mm}$ averaged from two orthogonal 2D views ${ }^{21}$. The TR coaptation zone is frequently non-circular and measures of vena contracta width relying on single $2 \mathrm{D}$ imaging may be inaccurate - planimetry using $3 \mathrm{D}$ colour assessment may therefore be conceptually more appropriate.

Accumulating evidence links EROA to outcome in various settings ${ }^{22,23}$ and current American Society of Echocardiography (ASE) and European Association of Cardiovascular Imaging (EACVI) guidelines define severe TR as an EROA $\geq 0.40 \mathrm{~cm}^{2}$ and $\mathrm{RVol} \geq 45 \mathrm{~mL}^{20,24}$. However, since patients undergoing transcatheter TV interventions (TTVI) frequently have an anatomical regurgitant area several times greater than an EROA of $0.40 \mathrm{~cm}^{2}$, an extended classification to include "massive" and "torrential" TR (both associated with detrimental outcomes) has recently been proposed (Supplementary Table 1) $^{23-27}$. Studies using cardiac magnetic resonance (CMR) quantitation suggest that patients with a TR regurgitant volume $\geq 45 \mathrm{ml}$ or regurgitant fraction $\geq 50 \%$ have the highest risk of excess mortality ${ }^{28}$ (Table 2).

\section{ASSESSMENT OF RV SIZE AND FUNCTION}

Comprehensive RV assessment in patients with severe TR should be performed in a euvolemic state and include standard echocardiographic measures of $\mathrm{RV}$ size and function, and quantification of $\mathrm{RV}$ morphological, functional, and tissue remodelling (Figure 2, Table 2). Standard echocardiographic measures of RV size and function are listed in Supplementary Table $\mathbf{2}^{29}$. Assessment of RV strain using 2D echocardiography or CMR is less load dependent than tricuspid annular plane systolic excursion (TAPSE) in severe TR and more sensitive in the detection of early RV dysfunction and prediction of overall clinical outcome ${ }^{30}$. RV ejection
Table 2. Imaging modalities for diagnosis of tricuspid valve disease and guidance of transcatheter tricuspid valve interventions.

\begin{tabular}{|c|c|}
\hline $\begin{array}{l}\text { Imaging } \\
\text { modality }\end{array}$ & Applications \\
\hline \multirow[t]{5}{*}{ TTE } & Grading of TR severity \\
\hline & $\begin{array}{l}\text { Assessment of TV pathology and mechanism(s) of } \\
\text { TR }\end{array}$ \\
\hline & Diagnosis/classification of PHT \\
\hline & Evaluation of RV function \\
\hline & $\begin{array}{l}\text { Determination of pacemaker/defibrillator lead } \\
\text { location and evaluation of TV leaflet lead } \\
\text { impingement }\end{array}$ \\
\hline \multirow[t]{5}{*}{ TEE (3D) } & $\begin{array}{l}\text { Assessment of TV pathology and mechanism(s) of } \\
\text { TR }\end{array}$ \\
\hline & Exclusion of intracardiac thrombus/masses \\
\hline & $\begin{array}{l}\text { Determination of pacemaker/defibrillator lead } \\
\text { location and evaluation of TV leaflet lead } \\
\text { impingement }\end{array}$ \\
\hline & $\begin{array}{l}\text { Evaluation of TEE imaging quality in supine } \\
\text { position }\end{array}$ \\
\hline & Procedural guidance \\
\hline \multirow[t]{3}{*}{ ICE (3D) } & $\begin{array}{l}\text { Procedural guidance in patients with insufficient } \\
\text { TEE quality or contraindications to oesophageal } \\
\text { intubation }\end{array}$ \\
\hline & Avoidance of extracardiac or left heart artefacts \\
\hline & $\begin{array}{l}\text { Elimination of the need for systematic general } \\
\text { anaesthesia }\end{array}$ \\
\hline \multirow[t]{7}{*}{ СCT } & $\begin{array}{l}\text { Assessment of annular shape, dimensions and } \\
\text { annular calcification }\end{array}$ \\
\hline & $\begin{array}{l}\text { Determination of the location of pacemaker/ } \\
\text { defibrillator leads }\end{array}$ \\
\hline & $\begin{array}{l}\text { Definition of optimal procedural fluoroscopic } \\
\text { angulations }\end{array}$ \\
\hline & $\begin{array}{l}\text { Assessment of the relationships of the tricuspid } \\
\text { annulus to surrounding structures (particularly the } \\
\text { RCA) }\end{array}$ \\
\hline & $\begin{array}{l}\text { Evaluation of specific annular anchor points in } \\
\text { relation to tricuspid leaflet hinge points and } \\
\text { coronary arteries }\end{array}$ \\
\hline & Evaluation of RCA status \\
\hline & $\begin{array}{l}\text { Evaluation of the relationship between IVC and TV } \\
\text { annulus }\end{array}$ \\
\hline \multirow{3}{*}{$\begin{array}{l}\text { Coronary } \\
\text { angiography/ } \\
\text { fluoroscopy }\end{array}$} & Evaluation of RCA status \\
\hline & $\begin{array}{l}\text { Navigation and control of patency of the RCA if } \\
\text { a device is anchored to the tricuspid annulus }\end{array}$ \\
\hline & $\begin{array}{l}\text { Orientation and device placement/deployment (in } \\
\text { particular in case of multiple implants) }\end{array}$ \\
\hline \multirow[t]{3}{*}{ CMR } & $\begin{array}{l}\text { Grading of TR severity when echocardiographic } \\
\text { quantification is inconclusive }\end{array}$ \\
\hline & Evaluation of RV function \\
\hline & Assessment of myocardial fibrosis \\
\hline \multicolumn{2}{|c|}{$\begin{array}{l}\text { CCT: cardiac computed tomography; CMR: cardiac magnetic resonance; } \\
\text { ICE: intracardiac echocardiography; IVC: inferior vena cava; } \\
\text { PHT: pulmonary hypertension; RCA: right coronary artery; RV: right } \\
\text { ventricle; TEE: transoesophageal echocardiography; TR: tricuspid } \\
\text { regurgitation; TTE: transthoracic echocardiography; TV: tricuspid valve }\end{array}$} \\
\hline
\end{tabular}




\section{Non-invasive imaging assessment of RV}

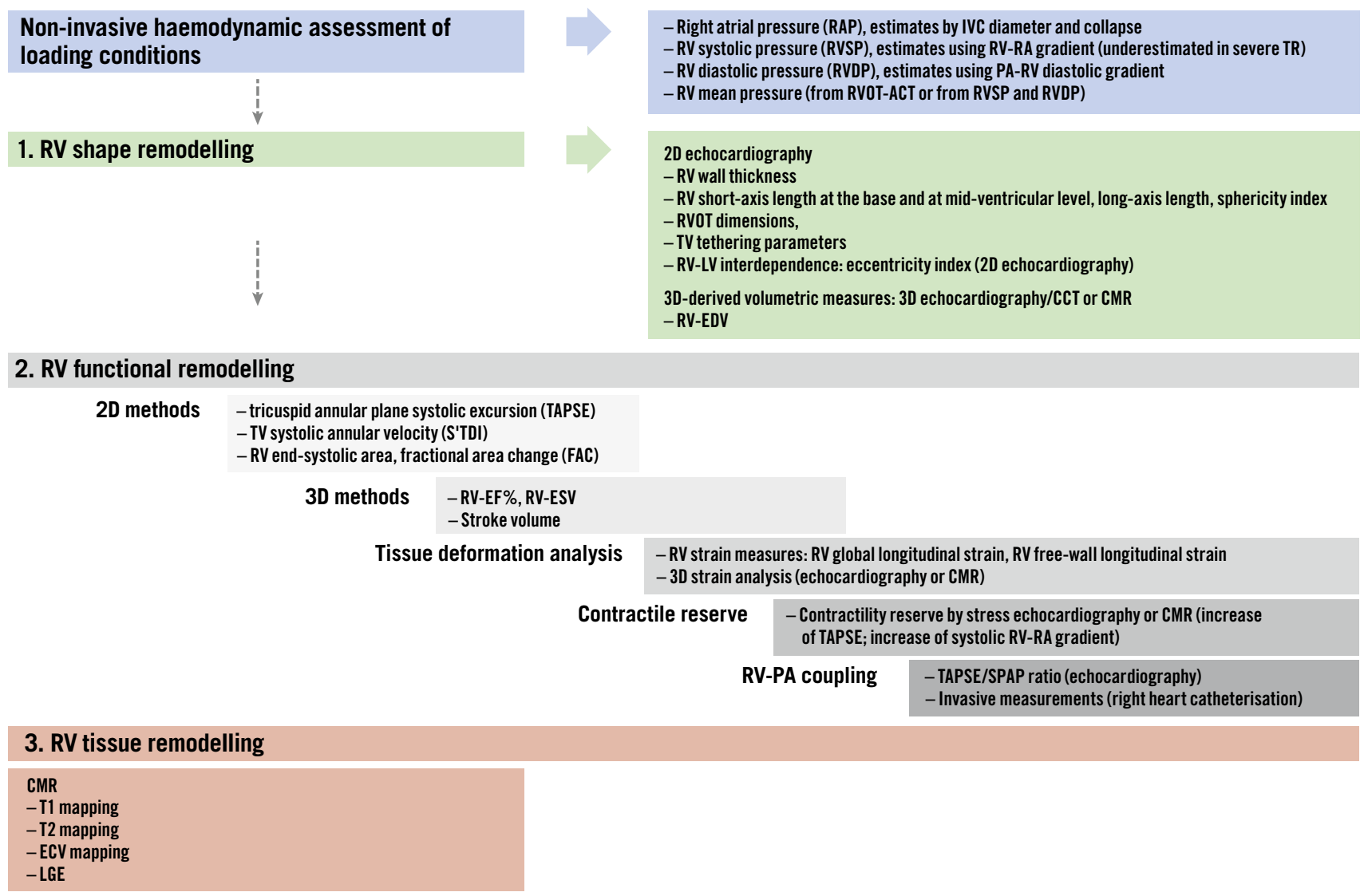

Figure 2. Imaging assessment of the right ventricle. 2D: two-dimensional; 3D: three-dimensional; ACT: acceleration time; CCT: cardiac computed tomography; CMR: cardiac magnetic resonance; ECV: extracellular volume; EDV: end-diastolic volume; EF: ejection fraction; ESV: end-systolic volume; IVC: inferior vena cava; LGE: late gadolinium enhancement; LV: left ventricle; PA: pulmonary artery; RV: right ventricle; RVOT: right ventricular outflow tract; SPAP: systolic pulmonary artery pressure; TV: tricuspid valve

fraction can be measured using various imaging modalities (CMR, $3 \mathrm{D}$ echocardiography, cardiac computed tomography [CCT]) but it fails to account for the relationship between RV contractility and afterload, and may therefore overestimate RV systolic function in severe TR. The TAPSE/systolic pulmonary artery pressure (SPAP) ratio, a non-invasive marker of RV-pulmonary arterial coupling, may overcome this limitation and its prognostic value has been demonstrated under several conditions ${ }^{31,32}$, including severe TR where a TAPSE/SPAP ratio $<0.31 \mathrm{~mm} / \mathrm{mmHg}$ indicates poor prog$\operatorname{nosis}^{33}$. In a recent propensity matched analysis, patients with midrange $\mathrm{RV}$ dysfunction (TAPSE 13-17 $\mathrm{mm}$ ) appeared to derive the greatest benefit from $\mathrm{TTVI}^{34}$.

The demonstration of contractile reserve in response to pharmacological or physical stress has prognostic relevance in patients with pulmonary hypertension and severe baseline RV dysfunction $^{35-37}$; further studies are needed to explore the role of stress imaging in severe TR.

Right heart catheterisation is the gold standard for the assessment of the severity and mechanism of PHT, pulmonary vascular resistance, RA pressure/pulmonary capillary wedge pressure ratio, pulmonary artery pulsatility index, and the reversibility of PHT $^{38,39}$. Moreover, an impaired afterload-corrected TAPSE to invasive SPAP obtained during right heart catheterisation and a discordant diagnosis of PHT $(>10 \mathrm{mmHg}$ difference between non-invasive and invasive SPAP) were independent predictors of worse outcomes (death, HF hospitalisation, and re-intervention) in patients with severe $\mathrm{TR}^{40}$.

Finally, detection of myocardial fibrosis by $\mathrm{CMR}^{41-43}$ has prognostic importance in RV failure and may help to define the optimal timing of intervention in severe TR.

\section{PATIENT MANAGEMENT AND SELECTION}

STR is associated with a variety of medical conditions and may present to a range of specialists (i.e., not only cardiologists). Efforts should be made to increase the clinical awareness of its consequences and emerging treatment options. All risk groups (those with left-sided heart disease, AF, previous mitral valve surgery, pre-capillary PHT, CIED RV lead) with symptoms/signs of congestive HF (jugular vein congestion, dyspnoea, peripheral oedema, renal failure, liver and gut congestion) should be 
specifically evaluated for the presence of significant STR. Initial consultation and echocardiography to confirm the diagnosis and assess TR severity and RV function should be followed by early referral to a centre with expertise in the treatment of TV disease where work-up may be completed by right and left heart catheterisation and advanced imaging studies (Table 2).

Currently, more than $90 \%$ of the patients with clinically relevant TR are not offered any treatment ${ }^{44}$, mainly due to the longstanding misconception that STR improves after treatment of left-sided heart disease, despite the fact that STR progresses in up to $25 \%$ of patients after open heart surgery ${ }^{11,12}$. Furthermore, relatively high mortality rates $(8.8 \%-9.7 \%)$ have been reported after conventional surgery for isolated TR, usually as a result of late referral ${ }^{45-48}$. However, according to single-centre studies including younger and less sick patients compared to the TTVI cohorts, tricuspid surgery may be safe and effective when performed in experienced centres ${ }^{49,50}$.

Regardless of symptomatic status and clinical presentation, patients with severe STR should first be treated for the assumed underlying condition (e.g., restore sinus rhythm in patients with AF if feasible, optimise medical treatment of HF or PHT) followed by re-evaluation using the same imaging modality (ideally at the same imaging laboratory) (Figure 3, Supplementary Table 3). Repositioning or extraction of CIED RV leads can be envisaged in selected patients with disturbed TV leaflet motion. However, the efficacy of this procedure in reducing TR is uncertain and additional damage to the TV valve can occur ${ }^{51}$.

The indication for any TV intervention and its timing should take account of multiple factors, including the patient's clinical characteristics, disease severity, concomitant end-organ function and anatomical considerations (Figure 4). Those who remain symptomatic and fluid overloaded despite diuretic treatment with mild or moderate left ventricular impairment, preserved RV function, no evidence of pre-capillary PHT, and only mild/moderate renal and liver dysfunction may derive the greatest benefit from TV intervention (Figure 4, central column). Combined procedures may be considered in patients with associated mitral or aortic valve disease $\mathrm{s}^{52}$ - a staged approach is often appropriate since TR and RV dimensions improve in about $40 \%$ of patients within three months of successful transcatheter treatment of mitral regurgitation ${ }^{53}$. Conversely, the procedure may be futile in candidates with end-stage HF, untreated pre- and post-capillary PHT or severe pulmonary fibrosis. Even if evidence is missing at this stage, advanced end-organ damage, i.e., terminal renal failure or manifest liver cirrhosis, need to be taken into account, in particular if the estimated life expectancy is less than one year (Figure 4, right column).

Patients presenting with refractory hypervolemic state before the procedure may benefit from in-patient medical treatment optimisation, in particular a course of intravenous diuretics. This may favourably modify right chamber anatomy, annulus size, and reduce large coaptation gaps, therefore facilitating interventional treatment.

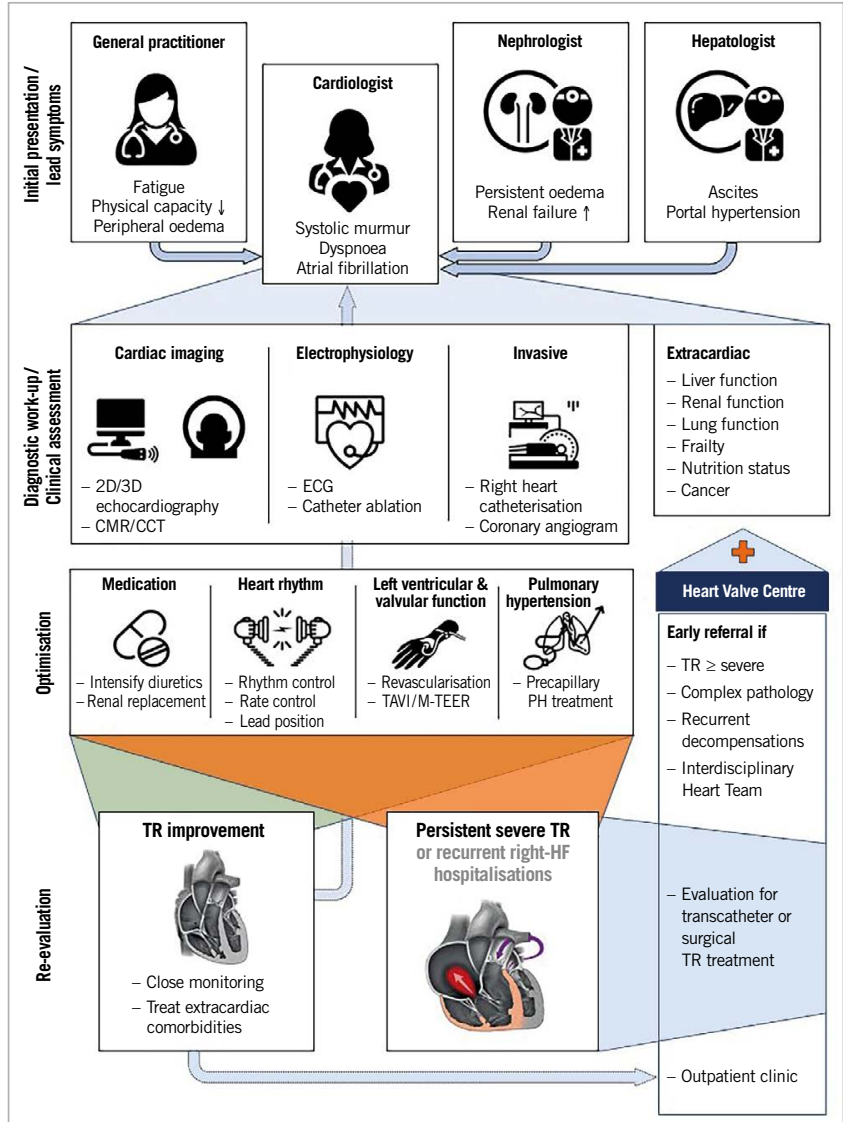

Figure 3. Care pathways for patients with severe tricuspid regurgitation. 2D: two-dimensional; 3D: three-dimensional; CCT: cardiac computed tomography; CMR: cardiac magnetic resonance; $E C G$ : electrocardiogram; $H F$ : heart failure; M-TEER: mitral transcatheter edge-to-edge reapair; PH: pulmonary hypertension; TAVI: transcatheter aortic valve implantation; TR: tricuspid regurgitation

\section{TRANSCATHETER TREATMENT OPTIONS AND DEVICE SELECTION}

Current transcatheter treatment options mimic surgical techniques and include approved solutions in Europe, such as leaflet approximation, direct annuloplasty and heterotopic caval valve implantation, as well as not yet commercially available transcatheter TV replacement (TTVR) systems using orthotopic valve implantation (Figure 5). Growing evidence supports the use of TTVI in inoperable or surgical high-risk patients: mortality was lower following intervention using various devices compared to standard medical treatment in two propensity score-matched cohorts ${ }^{34,54}$, accompanied by reduction in the rate of $\mathrm{HF}$ re-hospitalisation $(26 \pm 3 \%$ vs $47 \pm 3 \% \mathrm{p}<0.0001$ ) at one-year follow-up ${ }^{54}$. Confirmation of these findings in randomised controlled trials is needed.

Based on the aforementioned evidence, the 2021 Valvular Heart Disease guidelines of the European Society of Cardiology first give a IIb level $\mathrm{C}$ recommendation for transcatheter treatment of severe symptomatic TR in inoperable patients, while the importance of early referral of patients with TV disease, as well as the 


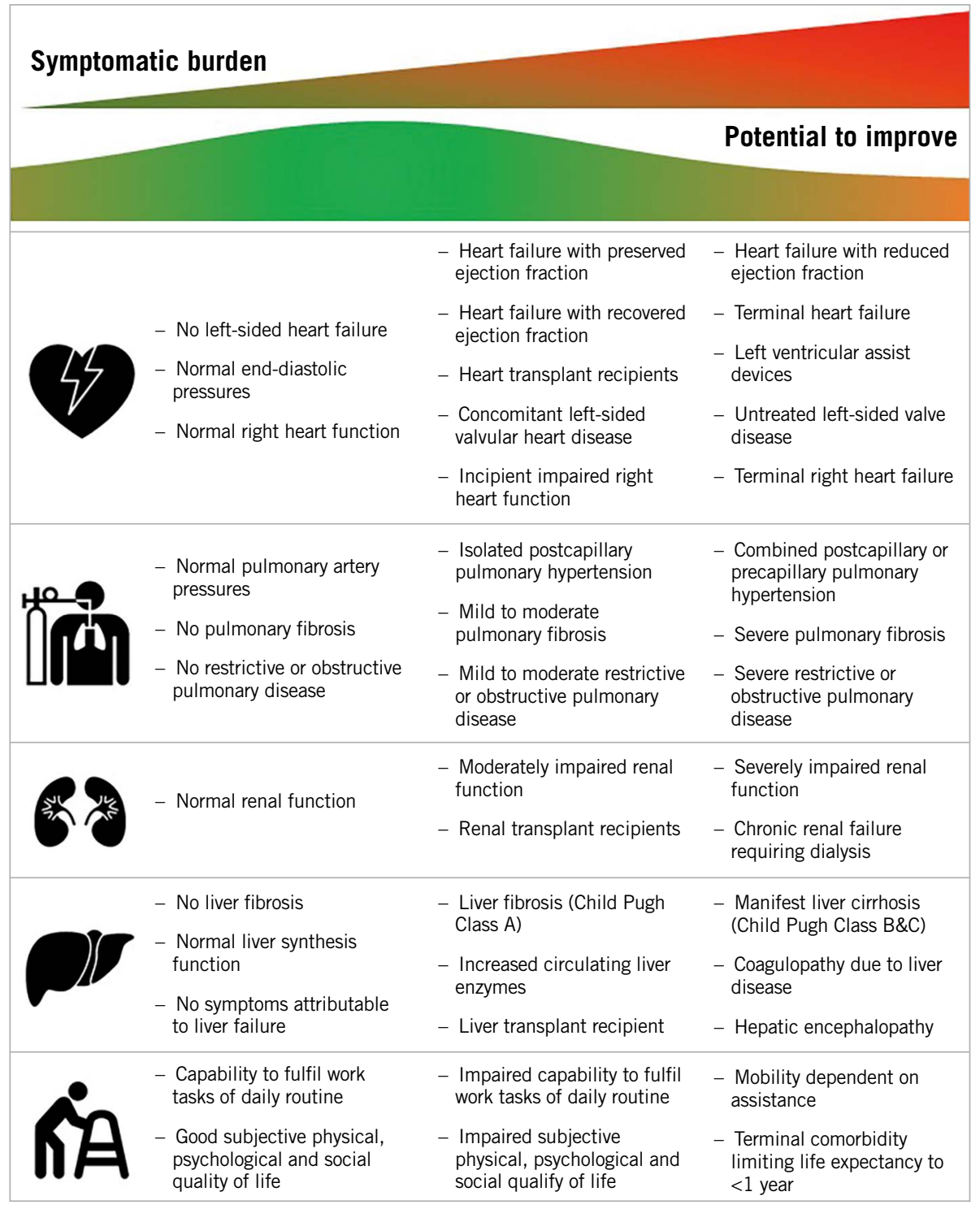

Figure 4. Clinical, anatomical and physiological factors suggesting a positive symptomatic response to tricuspid valve treatment.

role of concomitant treatment of the TV during left-sided heart surgery, are reinforced ${ }^{55}$.

Compared to mitral procedures, TTVI presents several additional technical and anatomical challenges, including difficult visualisation of the TV apparatus, variable anatomy with thinner valve leaflets, and a large coaptation gap. Proposed criteria and an algorithm used for device selection are shown in Table $\mathbf{3}$ and Figure 6.

\section{LEAFLET APPROXIMATION}

Tricuspid transcatheter edge-to-edge repair (T-TEER) using the TriClip $^{\mathrm{TM}}$ (Abbott Vascular, Santa Clara, CA, USA) or leaflet approximation with the PASCAL systems (Edwards Lifesciences, Irvine, CA, USA) are approved in Europe for minimally invasive TV repair. These techniques are the most frequently used worldwide as a result of their safety, availability, and ease of use.
Whilst initially performed "off-label" using the MitraClip ${ }^{\circledR}$ system (Abbott Vascular) ${ }^{56-58}$, a dedicated T-TEER device with a shorter curve guiding catheter and additional steerable plane of motion (septal to lateral), the TriClip, has been developed to facilitate TV access. In the core lab-adjudicated TRILUMINATE study, T-TEER in 85 prospectively enrolled patients (STR 84\%; severe, massive and torrential in $29 \%, 26 \%$ and $37 \%$, respectively) was associated with a durable reduction to moderate TR or less in $71 \%$ at one year, accompanied by symptomatic improvement $(83 \%$ of the patients were in New York Heart Association [NYHA] Class I or II at 12 months), and $40 \%$ reduction in the rate of re-hospitalisation ${ }^{59,60}$. In addition, improvement of the six-minute walking distance by $31 \pm 10.2$ metres and Kansas City Cardiomyopathy Questionnaire by $20 \pm 2.61$ points were observed, along with a significant reduction of the RV and RA dimensions and improvement 


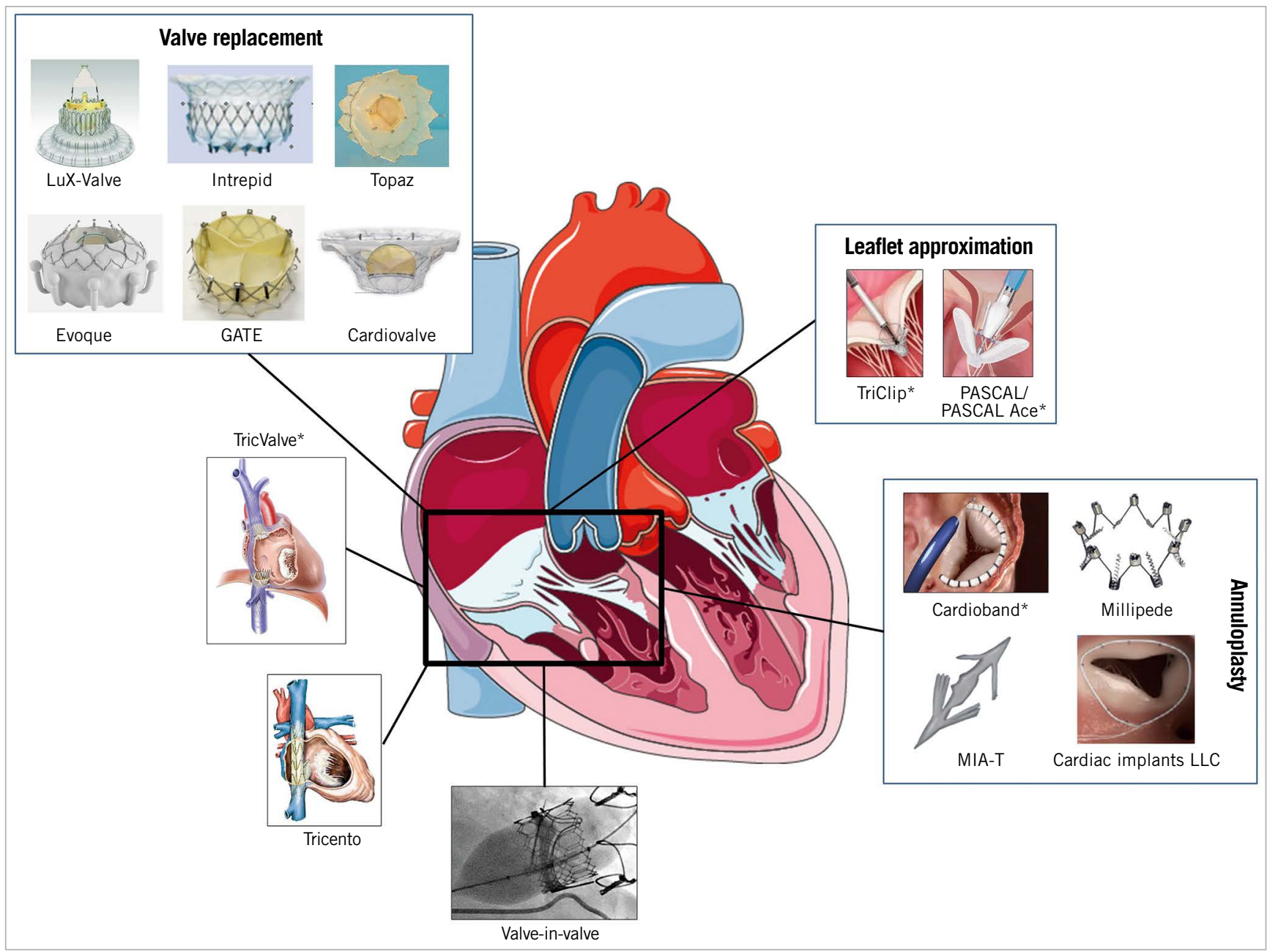

Figure 5. Transcatheter tricuspid systems that are approved or under clinical evaluation. * with CE approval.

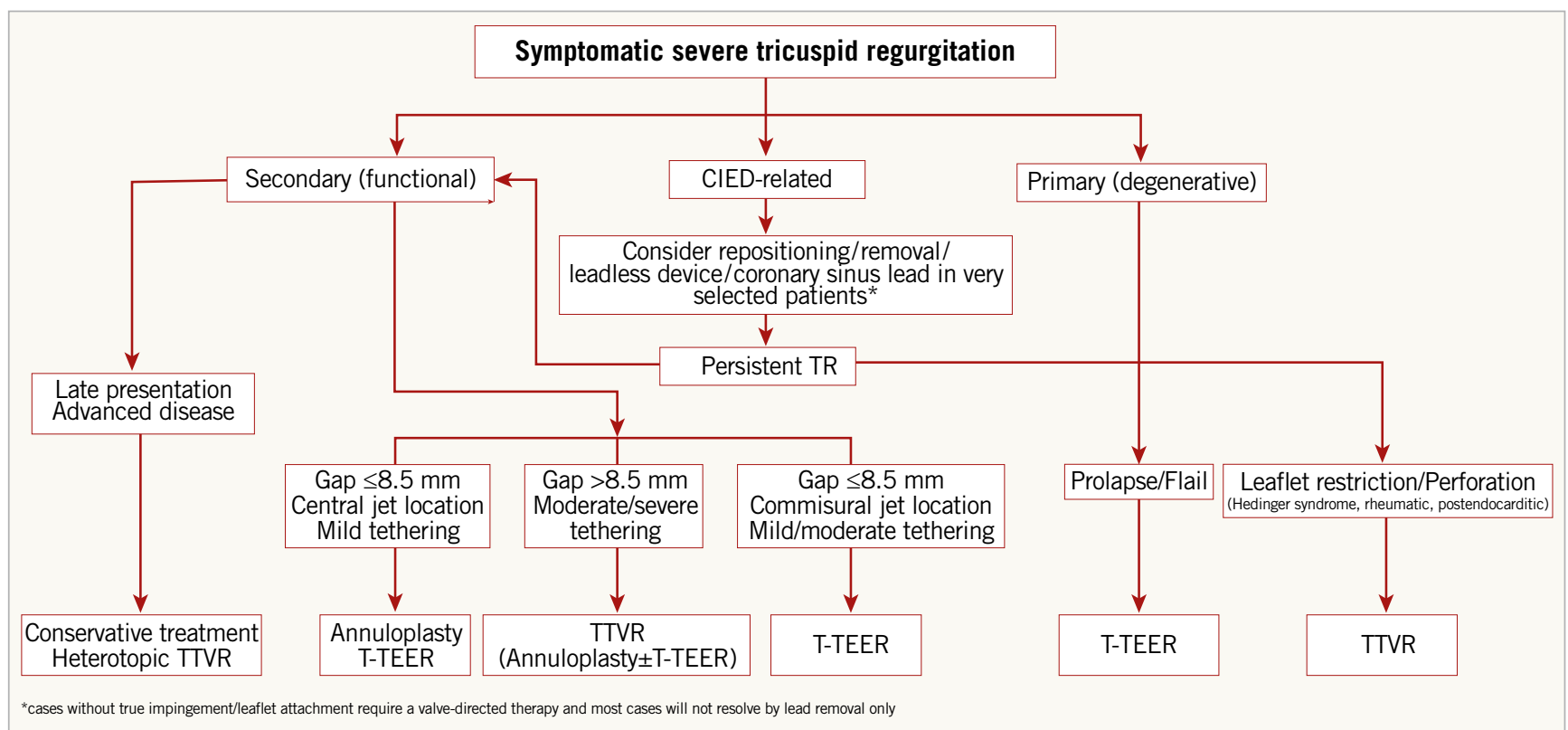

Figure 6. Proposed algorithm for the selection of TTVI systems. CIED: cardiac implantable electronic device; T-TEER: tricuspid transcatheter edge-to-edge repair; TTVR: transcatheter tricuspid valve replacement 
Table 3. Anatomical criteria for device selection.

\begin{tabular}{|c|c|c|c|}
\hline Strategy & Favourable anatomy & Feasible anatomy & Unfavourable anatomy \\
\hline $\begin{array}{l}\text { Leaflet } \\
\text { approximation }\end{array}$ & $\begin{array}{l}\text { Small septolateral gap } \leq 7 \mathrm{~mm}^{10} \\
\text { Anteroseptal jet location } \\
\text { Confined prolapse or flail } \\
\text { Trileaflet morphology }\end{array}$ & $\begin{array}{l}\text { Septolateral coaptation gap }>7 \text { but } \\
\leq 8.5 \mathrm{~mm}^{65} \\
\text { Posteroseptal jet location } \\
\text { Non-trileaflet morphology } \\
\text { Incidental CIED RV lead (i.e., without } \\
\text { leaflet impingement) }\end{array}$ & $\begin{array}{l}\text { Large septolateral coaptation gap } \\
>8.5 \mathrm{~mm}^{65} \\
\text { Leaflet thickening/shortening } \\
\text { (rheumatic, carcinoid)/perforation } \\
\text { Dense chordae with marked leaflet } \\
\text { tethering } \\
\text { Anteroposterior jet location } \\
\text { Poor echocardiographic leaflet } \\
\text { visualisation } \\
\text { CIED RV lead leaflet impingement } \\
\text { Unfavourable device angle of approach }\end{array}$ \\
\hline Annuloplasty & $\begin{array}{l}\text { Annular dilatation as primary } \\
\text { mechanism of TR } \\
\text { Mild tethering (tenting height } \\
<0.76 \mathrm{~cm} \text {, tenting area }<1.63 \mathrm{~cm}^{2}, \\
\text { tenting volume }[3 \mathrm{D}]<2.3 \mathrm{~mL})^{110,111} \\
\text { Central jet location } \\
\text { Sufficient landing zone for anchoring }\end{array}$ & $\begin{array}{l}\text { Moderate tethering (tethering height } \\
\geq 0.76 \mathrm{~cm} \text { but }<1.0 \mathrm{~cm} \text {, tenting area } \\
>1.63 \text { but }<2.5 \mathrm{~cm}^{2} \text {, tenting volume } \\
\text { [3D] } \geq 2.3 \mathrm{~mL} \text { but } \leq 3.5 \mathrm{~mL} \text { ) } \\
\text { Incidental } 111 \\
\text { leaflet impingement) }\end{array}$ & $\begin{array}{l}\text { Excessive annular dilatation (exceeding } \\
\text { device size) } \\
\text { Severe tethering (tethering height } \\
>1.0 \mathrm{~cm} \text {, tenting volume }>3.5 \mathrm{~mL} \text { ). } \\
\text { Poor echocardiographic annular } \\
\text { visualisation }{ }^{110,111} \\
\text { Annular proximity of RCA } \\
\text { CIED RV lead leaflet impingement }\end{array}$ \\
\hline $\begin{array}{l}\text { Orthotopic } \\
\text { valve } \\
\text { implantation }\end{array}$ & $\begin{array}{l}\text { Previous surgical repair or bioprosthetic } \\
\text { valve replacement } \\
\text { Leaflet thickening/shortening } \\
\text { (rheumatic, carcinoid) } \\
\text { Incidental CIED RV lead (i.e., without } \\
\text { leaflet impingement) } \\
\text { Any leaflet morphology }\end{array}$ & $\begin{array}{l}\text { Large coaptation gap } \\
\text { CIED RV lead leaflet impingement }\end{array}$ & $\begin{array}{l}\text { Excessive annular dilatation (exceeding } \\
\text { device size) } \\
\text { Unfavourable device angle of approach } \\
\text { Severe right ventricular dysfunction }\end{array}$ \\
\hline $\begin{array}{l}\text { Heterotopic } \\
\text { valve } \\
\text { implantation }\end{array}$ & $\begin{array}{l}\text { Appropriate caval diameters (and } \\
\text { intercaval distance) } \\
\text { No option for direct valve treatment }\end{array}$ & & $\begin{array}{l}\text { Proximity of the RA to the orifice of the } \\
\text { liver veins }(<10-12 \mathrm{~mm}) \\
\text { Severely increased pulmonary artery } \\
\text { and RA pressures due to the risk of } \\
\text { fracture of bicaval valved stents }\end{array}$ \\
\hline
\end{tabular}

of the RV systolic function. Previous observational studies have demonstrated reverse RV remodelling ${ }^{61}$, improved cardiac output $^{62}$, and reduction of liver enzymes in patients with documented congestion following T-TEER ${ }^{63}$. Early experience with the first version of the system identified an increased risk of single leaflet device attachement in comparison with mitral procedures (about $7 \%$ in the TRILUMINATE study). A large coaptation gap ( $>7$ $10 \mathrm{~mm}$ ) and non-anteroseptal location of the TR jet have also been associated with procedural failure with the same version of the device ${ }^{10,64}$. Using the XTR implant with extended clip arms, a coaption gap $\leq 8.4 \mathrm{~mm}$ predicted successful reduction to moderate TR or less (Table 3$)^{65}$. The latest TriClip Gen 4 iteration of the system offers four different implant sizes and controlled gripper actuation to permit optimised independent leaflet grasping.

Comparable results have been obtained with the PASCAL system in a compassionate use cohort ${ }^{30}$, as well as in a US-based early feasibility study ${ }^{66}$. Although less experience has been accumulated so far, the number of procedures has grown rapidly since introduction of the smaller PASCAL Ace (Edwards Lifesciences) device that facilitates navigation of the TV anatomy. The novel DragonFly ${ }^{\mathrm{TM}}$ transcatheter mitral valve repair device (Valgen Medical, Hong Kong, China) has recently been used successfully for mitral intervention $^{67}$, and its use for TV repair is under current investigation.

\section{ANNULOPLASTY}

The Cardioband ${ }^{\mathrm{TM}}$ direct annuloplasty system (Edwards Lifesciences) obtained CE mark for the treatment of patients with severe symptomatic STR in 2018. In the European approval study (TRI-REPAIR), the device - consisting of a screw-anchored adjustable band - was successfully implanted in all 30 patients with sustained reduction of TR to moderate or less in $76 \%$ at 30 days, $73 \%$ at 6 months $^{68}$ and $72 \%$ at 2 years ${ }^{69}$, and more than $80 \%$ of the patients in NYHA Class I/II throughout the follow-up period. Similarly, a $20 \%$ reduction in septolateral diameter was achieved in the post-market core laboratory adjudicated TriBAND study, translating into reduction of TR to moderate or less in $69 \%$ of patients at 30 days $^{70}$. Of note, patients included in both studies had higher EROA at baseline compared to those in TRILUMINATE (TRI-REPAIR $0.79 \pm 0.51$, TriBAND $0.76 \pm 0.48$, TRILUMINATE $0.65 \pm 0.03$ ), suggesting the inclusion of candidates with more advanced disease ${ }^{71}$. In another study including 
60 patients of whom $51.7 \%$ had massive or torrential and $48.3 \%$ severe TR, $60.3 \%$ of patients had less-than-severe TR at discharge $^{72}$. Particular care is required during deployment to avoid right coronary artery perforation or occlusion that occurred in $15 \%$ of the cases during the early experience (although transient deformation may not lead to clinical consequences) $)^{72,73}$. These results emphasise the need for further technical refinement along with careful patient selection and preprocedural planning.

Other annuloplasty techniques are under clinical investigations. The Millipede ring (Boston Scientific, Marlborough, MA, USA) has been implanted surgically in two patients ${ }^{74}$ and a transcatheter approach is in development. The MIA ${ }^{\mathrm{TM}}-\mathrm{T}$ system (Micro Interventional Devices, Newtown, PA, USA), a sutureless transcatheter annuloplasty system, is being investigated in a study (STTAR study) using both the surgical and transcatheter approach. Furthermore, successful implantation of a two-stage percutaneous annuloplasty system (Cardiac Implant LLC, Tarrytown, NY, USA) was reported in $2020^{75}$.

\section{TRANSCATHETER TRICUSPID VALVE REPLACEMENT}

TTVR was first performed in 2017 using the GATETM bioprosthesis (NaviGate Cardiac Structures, Inc., Lake Forest, CA, USA) that was introduced mainly via the transatrial surgical route using a 42 Fr catheter delivering an up to $54 \mathrm{~mm}$ stented valve $\mathrm{e}^{76,77}$. Technical success was achieved in 26/30 (87\%) consecutive patients with relevant conduction disturbances in $10 \%$ and conversion to open heart surgery in 5\%. In-hospital mortality was relatively high $(10 \%)$ in this early experience and inotropic support was required in $57 \%$ of patients, most probably due to transient RV failure ${ }^{7}$

The LuX-Valve (Ningbo Jenscare Biotechnology Co. Ltd., Ningbo, China) is another $32 \mathrm{Fr}$ system inserted via the transatrial access that can anchor to the septum and simultaneously grasp the anterior TV leaflet. Initial experience in 46 patients was associated with high technical success $(97.8 \%)$ - one patient developed fatal RV perforation - and an in-hospital mortality rate of $13 \%{ }^{79}$.

Surgical thoracotomy is associated with significant morbidity in patients with advanced disease, encouraging a move towards transfemoral systems. The EVOQUE bioprosthesis (Edwards Lifesciences) is delivered using a $28 \mathrm{Fr}$ catheter and is available in three sizes $(44,48$, and $52 \mathrm{~mm})$. The system has been investigated on a compassionate use basis in 25 patients with successful implantation in $92 \%$, reduction of TR to mild or trace in $100 \%$, and no deaths, coronary complications, or valve migration. A permanent pacemaker implantation was required in $8 \%$, and $76 \%$ of patients were in NYHA Class I/II at 30 days ${ }^{80}$. Preliminary results of the single-arm early TRISCEND feasibility study have been equally encouraging with an all-cause mortality rate of $3.8 \%$ at one month [Kodali S. TRISCEND study 30-day outcomes after transfemoral tricuspid valve replacement. EuroPCR 2021].

Transfemoral implantation of the Intrepid ${ }^{\mathrm{TM}}$ (Medtronic, Minneapolis, MN, USA) available in 42 and $48 \mathrm{~mm}$ sizes, the Cardiovalve (Cardiovalve Ltd., Or Yehuda, Israel), and the Topaz (TRiCares, Aschheim, Munich, Germany) transfemoral systems have also been reported in individual patients. Another self-expanding unileaflet stented bioprosthesis, the Trisol valve (Trisol Medical, Yokneam, Israel), is introduced via the jugular access and has recently been successfully used in humans.

Off-label transcatheter valve-in-valve implantation of the SAPIEN 3 aortic bioprosthesis (Edwards Lifesciences) is a safe and effective treatment option in patients with a degenerating surgical tricuspid bioprosthesis ${ }^{81}$, while suboptimal results have been observed after tricuspid valve-in-ring procedures ${ }^{82,83}$.

\section{HETEROTOPIC CAVAL VALVE IMPLANTATION}

Heterotopic caval valve implantation can mitigate symptoms related to TR and associated RV failure without treating its cause and is therefore a useful symptomatic treatment option in patients who are unsuitable for other transcatheter or surgical procedures. Conventional aortic balloon-expandable bioprostheses are too small in this setting and associated with deleterious embolic complications $^{84}$. This has led to the development of the dedicated TricValve $^{\circledR}$ (P+F Products + Features GmbH, Wessling, Germany) and TRICENTO ${ }^{\mathrm{M} 2 \mathrm{M}}$ (MEDIRA GmbH, Balingen, Germany) devices. While TricValve features two valves implanted separately in the superior and inferior vena cava, TRICENTO ${ }^{\mathrm{M} 2 \mathrm{M}}$ consists of a custom-made single valved stent linking both venae cavae. In their current iteration, both devices can treat patients with diameters of the inferior vena cava (IVC) up to $40-43 \mathrm{~mm}$, while the distance from the RA junction to the hepatic veins needs to be at least $10 \mathrm{~mm}$. Successful implantations of both devices have been reported in individual patients ${ }^{85-87}$, although recently described fractures of the TRICENTO ${ }^{\mathrm{M} 2 \mathrm{M}}$ stent frame in patients with massive or torrential TR have led to design modification and adjustement of clinical selection criteria. Further evaluation in larger cohorts is required to understand the role and implications of this therapy better.

\section{INTERVENTIONAL IMAGING}

3D-TEE is essential for intraprocedural guidance during TTVI and the mid- and deep-oesophageal (RV inflow/outflow) and transgastric windows are of particular value (Figure 7). Beyond leaflet approximation, all other transcatheter techniques require dedicated preprocedural CCT assessement of the tricuspid annular and subvalvular anatomy, as well as RA and caval dimensions ${ }^{88}$. Implant simulation and real-time fusion of CCT, fluoroscopy and echocardiographic images may also assist in some procedures.

It is essential to understand that interventionalists and imaging specialists approach the TV apparatus from different perspectives. During intraprocedural imaging, the TEE probe is behind the heart, generating TV images in the "valentine" position (Supplementary Figure 3A-Supplementary Figure 3C). However, movement of catheters during TTVI, spatial relationships of the TV with adjacent structures (particularly the IVC) and the direction of predominant annular dilation are better understood when labelling TV structures using the "attitudinal" nomenclature. CCT can also be used to demonstrate the anatomic relationships of the TV using a fluoroscopy-like display (Supplementary Figure 3DSupplementary Figure 3F). 


\begin{tabular}{|c|c|c|c|}
\hline View & Imaging examples & Structures imaged & Potential role in procedural guidance \\
\hline $\begin{array}{l}\text { 4-chamber view, } \\
\operatorname{ME}\left(0-30^{\circ}\right)\end{array}$ & $\sqrt{E}$ & $\begin{array}{l}\text { - Tricuspid valve (A, S) } \\
\text { - Right atrium/right ventricle/ } \\
\text { outflow } \\
\text { - Left atrium/ventricle } \\
\text { - Aortic valve }\end{array}$ & $\begin{array}{l}\text { - Septal and anterior tricuspid valve } \\
\text { leaflets (for TEER) and annulus (for } \\
\text { annular or replacement devices). }\end{array}$ \\
\hline $\begin{array}{l}\text { RV inflow/outflow view, } \\
\text { ME }\left(60-90^{\circ}\right)\end{array}$ & 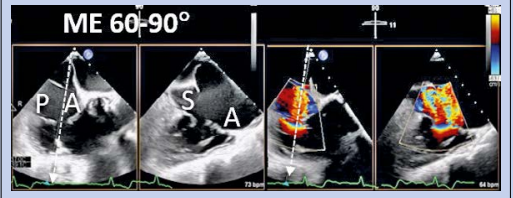 & $\begin{array}{l}\text { - Tricuspid valve }(A, P, S) \\
\text { - Right atrium/right ventricle }\end{array}$ & $\begin{array}{l}\text { - Imaging sweep from anterior to } \\
\text { posterior to localise regurgitant orifice } \\
\text { along the septal coaptation line. } \\
\text { - Biplane imaging used to visualise A-S } \\
\text { or P-S coaptation zone or annulus. }\end{array}$ \\
\hline $\begin{array}{l}\text { 2-chamber view, } \\
\mathrm{DE}\left(0-30^{\circ}\right) \text { and } \mathrm{RV} \\
\text { inflow/outflow view, DE } \\
\left(60-90^{\circ}\right)\end{array}$ & & $\begin{array}{l}\text { - Tricuspid valve (A or } \mathrm{P}, \mathrm{S} \text { ) } \\
\text { - Right atrium/right ventricle } \\
\text { - Coronary sinus }\end{array}$ & $\begin{array}{l}\text { - Septal and anterior (or posterior, } \\
\text { depending on depth/flexion) tricuspid } \\
\text { valve leaflets (for TEER) and annulus } \\
\text { (for annular or replacement devices). }\end{array}$ \\
\hline $\begin{array}{l}\text { Reversed 4-chamber } \\
\text { view, ME and DE } \\
\left(150-180^{\circ}\right)\end{array}$ & & $\begin{array}{l}\text { - Tricuspid valve (A, S) } \\
\text { - Right atrium/right ventricle }\end{array}$ & $\begin{array}{l}\text { - Septal and anterior tricuspid valve } \\
\text { leaflets (for TEER) and annulus (for } \\
\text { annular or replacement devices). }\end{array}$ \\
\hline $\begin{array}{l}\text { 2-chamber view, } \\
\text { TG }\left(30-60^{\circ}\right) \\
\text { Short-axis view, } \\
\text { TG }\left(30-60^{\circ}\right)\end{array}$ & & $\begin{array}{l}\text { - Tricuspid valve SAX (A, S, P or } \\
\text { atypical morphology) } \\
\text { - Regurgitant orifice (SAX) } \\
\text { - Right ventricular outflow }\end{array}$ & $\begin{array}{l}\text { - Tricuspid coaptation gaps, regurgitant } \\
\text { orifice location and chordal anatomy } \\
\text { help guide TEER. } \\
\text { - Posterior annulus well imaged for } \\
\text { annular or replacement device. }\end{array}$ \\
\hline $\begin{array}{l}\text { Apical view, } \\
\text { DT }\left(0-30^{\circ} \text { or }\right. \\
\left.120-150^{\circ}\right)\end{array}$ & & $\begin{array}{l}\text { - Tricuspid valve (A, S) } \\
\text { - Right atrium/right ventricle/ } \\
\text { outflow } \\
\text { - Left ventricular outflow } \\
\text { - Aortic valve }\end{array}$ & $\begin{array}{l}\text { - Septal and anterior tricuspid valve } \\
\text { leaflets (for TEER) and annulus (for } \\
\text { annular or replacement devices). } \\
\text { - TR Doppler aligned for quantitative } \\
\text { analysis. }\end{array}$ \\
\hline 3D volumes (any level) & & $\begin{array}{l}\text { - Tricuspid valve SAX (A, S, P or } \\
\text { atypical morphology) } \\
\text { - Regurgitant orifice (SAX) }\end{array}$ & $\begin{array}{l}\text { - 3D multiplanar reconstruction allows } \\
\text { simultaneous imaging of coaptation } \\
\text { gaps, regurgitant orifice location and } \\
\text { leaflet lengths/mobility for device } \\
\text { implantation. }\end{array}$ \\
\hline
\end{tabular}

Figure 7. TEE views during transcatheter TV intervention. Deep oesophageal view for biplane imaging and acquisition of $3 D$ volumes. The transgastric view is the only $2 D$ view that allows simultaneous visualisation of all three TV leaflets. 3D: three-dimensional; A: anterior; $D E$ : deep oesophageal; ME: mid-oesophageal; P: posterior; S: septal; TG: transgastric; RV: right ventricle; SAX: short axis;

TEER: transcatheter edge-to-edge repair

Clear and continuous communication and understanding between the interventional echocardiographist and TV interventionalist is key to procedural success. Speaking the same anatomical and directional language requires mutual knowledge of imaging, devices and the procedure, and can only be achieved by joint training of the TV transcatheter team. Standardisation of right chamber views using the "attitudinal" orientation and nomenclature (in which the displayed image and relationships of the TV leaflets with adjacent cardiac structures are identical irrespective of the imaging modality) provides the basis for a common language used by interventional and imaging specialists ${ }^{89}$.
Use of intracardiac echocardiography (ICE) is helpful in patients with insufficient imaging quality ${ }^{90-92}$ and will certainly increase once novel 4D catheters allowing 3D imaging and multiplanar reconstruction become broadly available ${ }^{93}$. This may reduce the need for general anesthesia in the future.

\section{POST-PROCEDURAL MANAGEMENT}

Since AF is highly prevalent in patients presenting with severe TR (about 70\%), post-procedural anticoagulation with either warfarin/coumadin or non-vitamin $\mathrm{K}$ antagonist oral anticoagulants (NOAC) is usually required. Patients in sinus rhythm with no other 
indication for anticoagulation should use the same antiplatelet regimen as after transcatheter mitral valve repair (usually four weeks of aspirin plus clopidogrel, followed by aspirin daily). The optimal antithrombotic regimen following TTVR is unclear, although early experience indicates that a warfarin-/coumadin-based anticoagulation regimen (possibly combined with aspirin for at least one year) might be preferred.

The preprocedural diuretic regimen should be maintained for at least three months after the procedure to allow RV reverse remodelling. However, careful dose reduction may be required in TTVR patients who develop early post-procedural polyuria (usually within 24-48 hours) as a result of improved cardiac output and reduced venous congestion, or in those who develop symptomatic hypotension and/or renal failure over longer-term follow-up. Given the need for frequent modification of the post-procedural diuretic and HF medication regimen, most sites recommend initial outpatient follow-up at 1, 6, and 12 months, followed by annual review. Assessment may include blood tests for NT-proBNP, renal and liver function, transthoracic echocardiography, a six-minute walk-test and a quality-of-life questionnaire.

Although systematic evidence is lacking, early experience suggests that glifozines (sodium glucose cotransporter 2 [SGLT-2] inhibitors) may be of particular benefit in selected patients with right-sided HF following TV intervention due to their diuretic, nephro-protective and symptomatic effects.

Periprocedural and early post-procedural antibiotic prophylaxis should be used in all patients undergoing TTVI to prevent infective endocarditis. After discharge, established endocarditis prophylaxis guidelines should be followed, although a lower threshold for treatment might be appropriate due to an increased probability of bacteraemia in the venous circulation.

\section{PROPOSED REQUIREMENTS FOR A HEART VALVE CENTRE WITH EXPERTISE IN TRICUSPID VALVE TREATMENT}

A multidisciplinary Heart Team approach is recommended for the evaluation of patients with TV disease in a Heart Valve Centre with expertise in a broad spectrum of diagnostic and therapeutic solutions (Table 4) ${ }^{94}$. Essential requirements include an interventional cardiology team with broad expertise in heart valve interventions, experience in advanced multimodality TV imaging (including high quality CCT and CMR for specific indications) and easy access to cardiac surgery counselling. A cardiac surgery department on site with operator experience in TV surgery, as well as an intermediate and intensive care unit (or alternatively a dedicated structural and valve unit) with collaborative links with other cardiac services (particularly an HF team) are mandatory, when investigational and replacement systems are used.

A Heart Valve Centre with expertise in TV treatment should build a referral and educational network with collaborating partners and offer easily accessible digital (imaging) data transfer solutions to enable remote consultation and case discussion. Finally, participation in multicentre studies assessing new treatment approaches for TR is of utmost importance given the need
Table 4. Proposed requirements for a heart valve centre with expertise in TV interventions.

\begin{tabular}{|c|c|}
\hline Minimal requirements & $\begin{array}{l}\text { Additional optional } \\
\text { requirements }\end{array}$ \\
\hline \multicolumn{2}{|l|}{ Interventional cardiology } \\
\hline $\begin{array}{l}\text { Expertise in valvular heart } \\
\text { intervention especially on the mitral } \\
\text { and tricuspid valves }\end{array}$ & $\begin{array}{l}\text { Experience in percutaneous } \\
\text { extracorporeal life support }\end{array}$ \\
\hline \multicolumn{2}{|l|}{ Cardiovascular imaging } \\
\hline $\begin{array}{l}2 \mathrm{D} / 3 \mathrm{D} \text { transthoracic and } \\
\text { transoesophageal echocardiography }\end{array}$ & (4D) ICE \\
\hline \multicolumn{2}{|l|}{ CCT and CMR } \\
\hline \multicolumn{2}{|l|}{ Cardiac surgery } \\
\hline $\begin{array}{l}\text { Access to expertise in valvular heart } \\
\text { surgery, (including aortic valve } \\
\text { replacement, mitral valve repair/ } \\
\text { replacement, tricuspid valve repair/ } \\
\text { replacement) }\end{array}$ & $\begin{array}{l}\text { Heart transplantation and } \\
\text { surgical circulatory support } \\
\text { programme }\end{array}$ \\
\hline \multicolumn{2}{|l|}{$\begin{array}{l}\text { Surgery on-site when investigational } \\
\text { and replacement systems are used }\end{array}$} \\
\hline \multicolumn{2}{|l|}{ Electrophysiology service } \\
\hline $\begin{array}{l}\text { Expertise in CRT, pacemaker and } \\
\text { ICD implantation, AF ablation }\end{array}$ & $\begin{array}{l}\text { Expertise in lead extraction } \\
\text { and repositioning, leadless } \\
\text { pacemaker implantation }\end{array}$ \\
\hline \multicolumn{2}{|l|}{ Intensive care unit } \\
\hline \multicolumn{2}{|l|}{$\begin{array}{l}\text { Dedicated beds with invasive } \\
\text { monitoring; expertise in } \\
\text { management of patients in } \\
\text { cardiogenic shock and requiring } \\
\text { mechanical circulatory support }\end{array}$} \\
\hline \multicolumn{2}{|l|}{ Collaborative services } \\
\hline Heart failure clinic & $\begin{array}{l}\text { Extracardiac specialties: } \\
\text { vascular surgery, neurology, } \\
\text { nephrology, hepatology, and } \\
\text { geriatrics }\end{array}$ \\
\hline \multicolumn{2}{|l|}{ Data review } \\
\hline \multicolumn{2}{|l|}{ Internal quality control } \\
\hline \multicolumn{2}{|l|}{$\begin{array}{l}\text { Involvement in national and } \\
\text { international databases }\end{array}$} \\
\hline \multicolumn{2}{|c|}{$\begin{array}{l}\text { 2D: two-dimensional; 3D: three-dimensional; 4D: four-dimensional; } \\
\text { AF: atrial fibrillation; CCT: cardiac computed tomography; CMR: cardiac } \\
\text { magnetic resonance; CRT: cardiac resynchronisation therapy; } \\
\text { ICD: implantable cardiac defibrillator; ICE: intracardiac } \\
\text { echocardiography }\end{array}$} \\
\hline
\end{tabular}

for greater understanding of the indications, timing and technical success of invasive TV treatments.

\section{FUTURE OUTLOOK AND CHALLENGES}

Although TTVI are rapidly emerging in response to an unmet clinical need, some important questions remain largely unanswered and require rapid resolution by means of large-scale registies and randomised studies:

- symptomatic and outcome benefits of STR correction compared to optimal medical treatment (TRILUMINATE, CLASP II TR, and TRISCEND II pivotal trials; TRI-FR; TRICI-HF)

- the appropriate timing of intervention in relation to clinical status, severity of TR, RV function and pulmonary artery pressure 
- criteria for concomitant or staged TTVI in conjunction with interventions for aortic and/or mitral valve disease

- comparative safety and efficacy of established and emerging transcatheter treatment options

- clinical and echocardiographic indicators to avoid futile interventions.

As a first priority, the wide variability of practice in relation to the diagnosis, assessment and timely management of TV disease should be addressed and unified across Europe, and programmes to increase awareness amongst primary and secondary care providers promoted.

Alongside the established $\mathrm{VARC}^{95}$ and $\mathrm{MVARC}^{96}$ criteria, the definition of standardised endpoints and definitions will ensure homogenous event reporting, accurate adjudication, and appropriate comparisons of clinical research studies involving new devices and therapeutic strategies for the treatment of TV disease. Given that endpoints of future studies are likely to be based largely on quality of life measures, levels of physical activity and assessement of volume status, new innovative concepts including wearable technology $^{97-99}$ and implantable HF monitoring devices will play an important role ${ }^{100}$. Since anatomical limitations, in particular large annulus size, still restrain eligibility, technological improvements are needed to address the needs of a broader population of patients. Advances in deep learning for the interpretation of echocardiographic, CCT and CMR images may further support standardisation and increase the accuracy of TR grading and assessement of RV function. These developments are set to accelerate rapidly in the next phase of the evolution of transcatheter valve interventions.

\section{Appendix. Study collaborators.}

Joao Cavalcante, MD, FASE, FACC, FSCCT, FSCMR; Minneapolis Heart Institute at Abbott Northwestern Hospital, Minneapolis, MN, USA. Gilles Dreyfus, MD, FRCS, FESC; Institut Mutualiste Montsouris, Paris, France. Alison Duncan, MB BS, PhD, FRCP; The Royal Brompton Hospital, London, UK. Mara Gavazzoni, MD; Cardiovascular Imaging Unit, Department of Cardiovascular, Neural and Metabolic Sciences, Instituto Auxologico Italiano, IRCCS, San Luca Hospital, Milan, Italy. Julia Grapsa, MD, PhD, FACC; Guy's and St Thomas' NHS Trust, London, UK. Edwin Ho, MD, FRCPC; Azeem Latib, MD, BCh; Montefiore Medical Center, New York, New York, USA. Nicolo Piazza, MD, PhD; McGill University Health Center, Montreal, Quebec, Canada. Maurice Sarano, MD; Mayo Clinic, Rochester, MN, USA. Marta Sitges, MD, PhD; Cardiovascular Institute, Hospital Clínic de Barcelona, Bacelona, Spain \& University of Barcelona, Barcelona, Spain. Martin Swaans, MD, PhD, FESC; St. Antonius Hospital, Nieuwegein, the Netherlands. Nina Wunderlich, MD, FACC; Cardiovascular Center Darmstadt, Darmstadt, Germany. Michel Zuber, MD, FESC; Cantonal Hospital, Aarau, Switzerland. Andrea Guidotti, MS; Simulands Ltd, Zurich, Switzerland. Scott Lim, MD; University of Virginia, Charlottesville, VA, USA. Chaim Lotan, MD, FACC, FESC; Hadassah University Hospital, Jerusalem, Israel. Thomas Modine, MD; Cardiovascular Surgery Department, Cœur Poumon CHU de Lille, Lille, France. Luis Ortega-Paz, MD, PhD;
Cardiovascular Institute, Hospital Clinic, IDIBAPS, Barcelona, Spain \& Division of Cardiology, University of Florida College of Medicine, Jacksonville, FL, USA. Lars Sondergaard, MD; The Heart Centre, Rigshospitalet, Copenhagen University Hospital, Copenhagen, Denmark. Hendrick Treede, MD; Department of Cardiac and Vascular Surgery, University Hospital Mainz, Johannes Gutenberg-University Mainz, Mainz, Germany. Rudiger Lange, MD; Department of Cardiovascular Surgery, German Heart Center Munich, Technische Universität München, Munich, Germany; Insure (Institute of Translational Cardiac Surgery), Department of Cardiovascular Surgery, German Heart Center Munich, Technische Universität München, Munich, Germany; DZHK (German Center for Cardiovascular Research) - Partner Site Munich Heart Alliance, Munich, Germany. Marianna Adamo, MD; Cardiac Catheterization Laboratory, ASST Spedali Civili di Brescia, Brescia, Italy. Martin Andreas, MD, MBA, PhD, MEBCTS; Department of Cardiac Surgery, Medical University of Vienna, Vienna, Austria. Stephan Baldus, MD; Department of Cardiology, University Heart Center, Cologne, Germany. Paolo Denti, MD; Progressive Cardiac Surgeon, San Raffaele University Hospital, Milan, Italy. Nicolas Dumonteil, MD; Clinique Pasteur, Toulouse, France; Didier Tchétché, MD; Clinique Pasteur, Toulouse, France; Rodrigo Estevez-Loureiro, MD, PhD, FESC; Interventional Cardiology Unit, University Hospital Alvaro Cunqueiro, Vigo, Spain. Luigi Fiocca, MD; Cardiovascular Department Papa Giovanni XXIII Hospital, Bergamo, Italy. Kai Friedrichs, MD; Herz- und Diabeteszentrum Nordrhein-Westfalen, Universitätsklinik der RuhrUniversität Bochum, Bad Oeynhausen, Germany. Carmelo Grasso, MD; Cardio-Toraco-Vascular Department - CAST AOU Policlinico “G. Rodolico-S. Marco”, Catania, Italy. Nicole Karam, MD, PhD; Université de Paris, PARCC, INSERM, F-75015, European Hospital Georges Pompidou, Paris, France. Wolfgang Rottbauer, MD, $\mathrm{PhD}$; Department of Internal Medicine II (Cardiology, Angiology, Pneumology, Intensive Care Unit), Ulm University Medical Center, Ulm, Germany. Volker Rudolph, MD; General and Interventional Cardiology, Heart \& Diabetes Center NRW, University Hospital of the Ruhr University of Bochum, Bad Oeynhausen, Germany. Keti Vitanova, MD; Department of Cardiovascular Surgery, German Heart Center Munich, Technische Universität München, Munich, Germany and Insure (Institute of Translational Cardiac Surgery), Department of Cardiovascular Surgery, German Heart Center Munich, Technische Universität München, Munich, Germany. Jeroen Bax, MD, PhD, FESC, FACC; Department of Cardiology, Leiden University Medical Centre (LUMC), Leiden, the Netherlands. Michael Borger, MD, PhD; University Clinic of Cardiac Surgery, Leipzig Heart Center, Leipzig, Germany. Erwan Donal, MD, PhD; University of Rennes, CHU Rennes, Inserm, LTSI - UMR 1099, Rennes, France. Helge Möllmann, MD, PhD; Department of Cardiology, St. Johannes Hospital, Dortmund, Germany. Osama Soliman, MD, PhD, FACC, FESC; Department of Cardiology, Saolta Group, Galway University Hospital, Health Service Executive and National University of Ireland Galway (NUIG), Galway, Ireland. Maurizio Taramasso, MD, PhD, HerzZentrum Hirslanden Zurich, 
Zurich, Switzerland. Holger Thiele, MD, FESC; Heart Center Leipzig at University of Leipzig, Department of Internal Medicine/ Cardiology, Leipzig, Germany. Nicolas van Mieghem, MD, $\mathrm{PhD}$; Department of Interventional Cardiology, Erasmus University Medical Centre, Rotterdam, the Netherlands. Stephan Windecker, MD; Department of Cardiology, Bern University Hospital, University of Bern, Bern, Switzerland. Luigi Badano, MD, PhD; Multimodality Cardiovascular Imaging Center, Department of Medicine and Surgery, University of Milano-Bicocca, Milan, Italy \& Department of Cardiology, Metabolic and Neural Sciences, San Luca Hospital, Istituto Auxologico Italiano, IRCCCS, Milan, Italy. Manuel Barreiro, MD, PhD, FESC; Cardiovascular Imaging, Cardiology Department, University Hospital Alvaro Cunqueiro, Vigo, Spain. Lenard Conradi, MD; University Heart and Vascular Center Hamburg, Department of Cardiovascular Surgery, University Medical Center HamburgEppendorf, Hamburg, Germany. Neil Fam, MD MSc; St. Michael's Hospital, University of Toronto, Toronto, Canada. Xavier Freixa, $\mathrm{MD}, \mathrm{PhD}$; Hospital Clinic of Barcelona. University of Barcelona. IDIBAPS. Barcelona, Spain. Marco Metra, MD; University and Civil Hospitals of Brescia, Brescia, Italy. Gilbert Tang, MBA, MSc, MD; Department of Cardiovascular Surgery, Mount Sinai Health System, New York, NY, USA. Yan Topilsky, MD; Cardiovascular Imaging, Cardiology Department, Tel Aviv Medical Center, Tel Aviv, Israel. Alec Vahanian, MD; University of Paris, Paris, France. William Wijns, MD; The Lambe Institute for Translational Medicine and Curam, National University of Ireland Galway, Galway, Ireland.

\section{Conflict of interest statement}

F. Praz has received travel expenses from Abbott Vascular, Edwards Lifesciences, and Polares Medical. D. Muraru is part of the speaker's bureau for GE Healthcare and received research equipment support from GE Vingmed. F. Kreidel has received speaker's honoraria from Abbott Vascular. P. Lurtz has served as a consultant for Abbott Structural Heart, Edwards Lifesciences, and Medtronic. R. Hahn has received speaker fees from Boston Scientific, Baylis Medical, Edwards Lifescience and Medtronic, consulting fees for Abbott Structural, Edwards Lifesciences, Gore\&Associates, Medtronic, Navigate, and Philips Healthcare, non-financial support from 3mensio, has equity with Navigate, and is the Chief Scientific Officer for the Echocardiography Core Laboratory at the Cardiovascular Research Foundation for multiple industry-sponsored trials, for which she receives no direct industry compensation. V. Delgado has received speaker fees from Abbott Vascular, Edwards Lifesciences, GE Healthcare, Novartis, MSD and Medtronic. M. Senni has received personal fees from Novartis during the conduct of the study and personal fees from Bayer, Abbott, Merck, AstraZeneca, Vifor Pharma and Boehringer outside the submitted work. R.S. von Bardeleben is a consultant for Abbott Vascular. G. Nickenig has received research funding from the Deutsche Forschungsgemeinschaft, the German Federal Ministry of Education and Research, the EU, Abbott, Edwards Lifesciences, Medtronic, and St. Jude Medical, and has received honoraria for lectures or advisory boards from Abbott, Edwards
Lifesciences, Medtronic, and St. Jude Medical. J. Hausleiter has received speaker honoraria from Abbott Vascular and Edwards Lifesciences. A. Mangieri has received an institutional grant from Boston Scientific and is part of the advisory board of Boston Scientific. J. Zamorano has received speaker honoraria from Daichii Sankyo and Pfizer. B. Prendergast has received unrestricted educational and research grants from Edwards Lifesciences and speaker/consultancy fees from Edwards Lifesciences, Abbott, and Anteris. F. Maisano reports grant and/or research institutional support from Abbott, Medtronic, Edwards Lifesciences, Biotronik, Boston Scientific Corporation, NVT, and Terumo, consulting fees, honoraria (personal and institutional) from Abbott, Medtronic, Edwards Lifesciences, Xeltis, Cardiovalve, Occlufit, Simulands, has royalty income/IP rights from Edwards Lifesciences, and is a shareholder (including share options) of Cardiogard, Magenta, SwissVortex, Transseptalsolutions, Occlufit, 4Tech, and Perifect. M. Adamo has no conflicts of interest to declare. M. Andreas reports receiving grants and fees from Edwards Lifesciences, Abbott, and Medtronic. L. Badano reports receiving consulting fees from Edwards Lifesciences, Esaote, and Jansen, and speaker fees from GE Healthcare, Esaote, and Philips. S. Baldus reports receiving a research grant Abbott, and speaker fees from Abbott and Edwards. M. Barreiro reports receiving speaker fees Abbott Vascular, Philips Healthcare and Boston Scientific. J. Bax reports receiving speaker fees Edwards Lifesciences and Abbott. M. Borger reports that his hospital receives consulting fees and/or speakers' honoraria on his behalf from Edwards Lifesciences, Medtronic, Abbott and CryoLife. J. Cavalcante reports receiving consulting fees Edwards Lifesciences, Abbott Structural, Medtronic, Inc., Boston Scientific, and VDYNE. L. Conradi reports receiving consulting and speaker fees from Edwards Lifesciences, Boston Scientific, Medtronic, and Abbott. P. Denti reports receiving a consulting fee from InnovHeart, and speaker fees from Abbott and Edwards. E. Donal reports receiving speaker fees from Abbott Vascular, Philips Healthcare and Boston Scientific. G. Dreyfus reports being a consultant from Edwards Lifesciences. N. Dumonteil reports receiving consulting and speaker fees from Abbott Vascular, Ancora Heart, Boston Scientific, Edwards Lifesciences, and Medtronic. A. Duncan reports lectures/ presentations for Abbott Vascular, Edwards Lifesciences, and Boston Scientific. R. Estevez-Loureiro reports receiving speaker fees Abbott Vascular, Edwards Lifesciences, and Boston Scientific. N. Fam has no conflicts of interest to declare. L. Fiocca has no conflicts of interest to declare. X. Freixa reports receiving consulting and speaker fees from Abbott Vascular. K. Friedrichs reports receiving grants from Edwards Lifesciences. M. Gavazzoni reports receiving personal fees from Abbott Vascular. J. Grapsa has no conflicts of interest to declare. C. Grasso reports receiving fees from Abbott Medical, Boston Scientific, and Edwards Lifesciences. A. Guidotti has no conflicts of interest to declare. E. Ho reports receiving support for attending meetings from Abbott, Edwards Lifesciences, and Medtronic. N. Karam reports receiving consulting fees from Abbott, Edwards Lifesciences, and 
Medtronic, and speaker fees from Edwards Lifesciences. R. Lange reports receiving consulting fees and royalties from Medtronic. A. Latib reports receiving consulting fees from Edwards Lifesciences, Abbott, Medtronic, and Boston Scientific. S. Lim reports receiving grants from Abbott Vascular and Edwards Lifesciences. C. Lotan has no conflicts of interest to declare. M. Metra reports receiving consulting fees from Amgen, AstraZeneca, Servier, Vifor Pharma, and WindTree Therapeutics, and speaker fees from Abbott Vascular, and Edwards Therapeutics. T. Modine is a consultant for Boston Scientific, Medtronic, Edwards, MicroPort, GE, and Abbott, and has received a research support grant from Edwards. H. Möllmann reports receiving consulting and speaker fees from Abbott Vascular, Boston Scientific and Edwards Lifesciences. L. Ortega-Paz has no conflicts of interest to declare. N. Piazza reports receiving consulting fees from Medtronic, Peijia Medical, and Highlife. W. Rottbauer reports receiving funding for this ms from Edwards Lifesciences, and consulting fees from Edwards Lifesciences and Abbott. V. Rudolph reports receiving grants from Edwards Lifesciences and Abbott Vascular. M. Sarano has no conflicts of interest to declare. M. Sitges reports receiving grants from Abbott, Medtronic, and Edward Lifesciences, and consulting and speaker fees from Abbott, Medtronic, and Edwards Lifesciences. O. Soliman has no conflicts of interest to declare. L. Sondergaard reports receiving consulting and speaker fees from Abbott, Boston Scientific, Medtronic, and SMT. M. Swaans reports receiving consulting fees from BioVentrix, Inc., and speakers fees from Abbott Vascular, Edwards Lifesciences, and Philips Healthcare. G. Tang reports receiving consulting and speaker fees from Abbott Structural Heart and Medtronic. M. Taramasso repors receiving consultant fees from Abbott, Edwards Lifesciences, Shenqi Medical, Boston Scientific, 4tech, CoreMedic, Simulands, MTEx, and Occlufit, and speaker fees from Abbott, and Edwards Lifesciences. D. Tchétché reports receiving consulting fees Abbott, Boston, Edwards, and Medtronic. H. Thiele has no conflicts of interest to declare. Y. Topilsky reports receiving consulting fees from Edwards, and MitralTech, and speaker fees from Edwards, and Abbott. H. Treede has received research support from Abbott Vascular, Boston Scientific, Edwards Lifesciences, JenaValve Technology, Medtronic, Tricares and Abiomed. A. Vahanian reports consultancy for CardioValve, and receiving consulting fees from Abbott Vascular, Edwards Lifescience, and Medtronic. N. van Mieghem has received grants and personal fees from Abbott Vascular, Medtronic, Boston Scientific, and PulseCath BV. K. Vitanova reports receiving speakers honoraria from Medtronic. S. Windecker reports receiving research and educational grants to the institution from Abbott, Amgen, BMS, Bayer, Boston Scientific, Biotronik, Cardinal Health, CSL Behring, Daiichi Sankyo, Edwards Lifesciences, Johnson\&Johnson, Medtronic, Querbet, Polares, Sanofi, Terumo, and Sinomed. N. Wunderlich reports receiving consulting fees from Edwards Lifesciences, Holitstick Medical and Cardiac Implants, and speaker fees from Cardiac Dimension, GE, Philipps, Gore, Abbott, Edwards Lifesciences, Occlutech, and Alnylam. M. Zuber has received fees from Edwards Lifesciences, and Abbott.

\section{References}

1. Nishimura RA, Otto CM, Bonow RO, Carabello BA, Erwin JP 3rd, Guyton RA, O'Gara PT, Ruiz CE, Skubas NJ, Sorajja P, Sundt TM 3rd, Thomas JD; American College of Cardiology/American Heart Association Task Force on Practice Guidelines. 2014 AHA/ACC guideline for the management of patients with valvular heart disease: a report of the American College of Cardiology/American Heart Association Task Force on Practice Guidelines. J Am Coll Cardiol. 2014;63:e57-185.

2. Topilsky Y, Maltais S, Medina Inojosa J, Oguz D, Michelena H, Maalouf J, Mahoney DW, Enriquez-Sarano M. Burden of Tricuspid Regurgitation in Patients Diagnosed in the Community Setting. JACC Cardiovasc Imaging. 2019;12:433-42.

3. Nath J, Foster E, Heidenreich PA. Impact of tricuspid regurgitation on long-term survival. J Am Coll Cardiol. 2004;43:405-9.

4. Topilsky Y, Nkomo VT, Vatury O, Michelena HI, Letourneau T, Suri RM, Pislaru S, Park S, Mahoney DW, Biner S, Enriquez-Sarano M. Clinical outcome of isolated tricuspid regurgitation. JACC Cardiovasc Imaging. 2014;7:1185-94.

5. Chorin E, Rozenbaum Z, Topilsky Y, Konigstein M, Ziv-Baran T, Richert E, Keren G, Banai S. Tricuspid regurgitation and long-term clinical outcomes. Eur Heart J Cardiovasc Imaging. 2020;21:157-65.

6. Holda MK, Zhingre Sanchez JD, Bateman MG, Iaizzo PA. Right Atrioventricular Valve Leaflet Morphology Redefined: Implications for Transcatheter Repair Procedures. JACC Cardiovasc Interv. 2019;12:169-78.

7. Xanthos T, Dalivigkas I, Ekmektzoglou KA. Anatomic variations of the cardiac valves and papillary muscles of the right heart. Ital J Anat Embryol. 2011;116:111-26. 8. Wafae N, Hayashi H, Gerola LR, Vieira MC. Anatomical study of the human tricuspid valve. Surg Radiol Anat. 1990;12:37-41.

9. Hahn RT, Weckbach LT, Noack T, Hamid N, Kitamura M, Bae R, Lurz P, Kodali SK, Sorajja P, Hausleiter J, Nabauer M. Proposal for a Standard Echocardiographic Tricuspid Valve Nomenclature. JACC Cardiovasc Imaging. 2021;14:1299-305.

10. Besler C, Orban M, Rommel KP, Braun D, Patel M, Hagl C, Borger M, Nabauer M, Massberg S, Thiele H, Hausleiter J, Lurz P. Predictors of Procedural and Clinical Outcomes in Patients With Symptomatic Tricuspid Regurgitation Undergoing Transcatheter Edge-to-Edge Repair. JACC Cardiovasc Interv. 2018;11:1119-28.

11. Song H, Kim MJ, Chung CH, Choo SJ, Song MG, Song JM, Kang DH, Lee JW, Song JK. Factors associated with development of late significant tricuspid regurgitation after successful left-sided valve surgery. Heart. 2009;95:931-6.

12. Kwak JJ, Kim YJ, Kim MK, Kim HK, Park JS, Kim KH, Kim KB, Ahn H, Sohn DW, Oh BH, Park YB. Development of tricuspid regurgitation late after leftsided valve surgery: a single-center experience with long-term echocardiographic examinations. Am Heart J. 2008;155:732-7.

13. Kim JB, Spevack DM, Tunick PA, Bullinga JR, Kronzon I, Chinitz LA, Reynolds HR. The effect of transvenous pacemaker and implantable cardioverter defibrillator lead placement on tricuspid valve function: an observational study. $J \mathrm{Am} \mathrm{Soc}$ Echocardiogr. 2008;21:284-7.

14. Höke U, Auger D, Thijssen J, Wolterbeek R, van der Velde ET, Holman ER, Schalij MJ, Bax JJ, Delgado V, Marsan NA. Significant lead-induced tricuspid regurgitation is associated with poor prognosis at long-term follow-up. Heart. 2014;100: 960-8.

15. Anvardeen K, Rao R, Hazra S, Hay K, Dai H, Stoyanov N, Birnie D, Dwivedi G, Chan KL. Prevalence and Significance of Tricuspid Regurgitation Post-Endocardial Lead Placement. JACC Cardiovasc Imaging. 2019;12:562-4.

16. Prihadi EA, van der Bijl P, Gursoy E, Abou R, Mara Vollema E, Hahn RT, Stone GW, Leon MB, Ajmone Marsan N, Delgado V, Bax JJ. Development of significant tricuspid regurgitation over time and prognostic implications: new insights into natural history. Eur Heart J. 2018;39:3574-81.

17. Antunes MJ, Rodriguez-Palomares J, Prendergast B, De Bonis M, Rosenhek R, Al-Attar N, Barili F, Casselman F, Folliguet T, Iung B, Lancellotti P, Muneretto C, Obadia JF, Pierard L, Suwalski P, Zamorano P; ESC Working Groups of Cardiovascular Surgery and Valvular Heart Disease. Management of tricuspid valve regurgitation: Position statement of the European Society of Cardiology Working Groups of Cardiovascular Surgery and Valvular Heart Disease. Eur J Cardiothorac Surg. 2017; 52:1022-30.

18. Muraru D, Badano LP, Nagata Y, Surkova E, Nabeshima Y, Genovese D, Otsuji Y, Guida V, Azzolina D, Palermo C, Takeuchi M. Development and prognostic validation of partition values to grade right ventricular dysfunction severity using $3 \mathrm{D}$ echocardiography. Eur Heart J Cardiovasc Imaging. 2020;21:10-21.

19. Lancellotti P, Tribouilloy C, Hagendorff A, Popescu BA, Edvardsen T, Pierard LA, Badano L, Zamorano JL; Scientific Document Committee of the European Association of Cardiovascular Imaging. Recommendations for the echocardiographic assessment of native valvular regurgitation: an executive summary from the European Association of Cardiovascular Imaging. Eur Heart J Cardiovasc Imaging. 2013;14:611-44.

20. Zoghbi WA, Adams D, Bonow RO, Enriquez-Sarano M, Foster E, Grayburn PA, Hahn RT, Han Y, Hung J, Lang RM, Little SH, Shah DJ, Shernan S, Thavendiranathan P, 
Thomas JD, Weissman NJ. Recommendations for Noninvasive Evaluation of Native Valvular Regurgitation: A Report from the American Society of Echocardiography Developed in Collaboration with the Society for Cardiovascular Magnetic Resonance. J Am Soc Echocardiogr. 2017;30:303-71.

21. Dahou A, Ong G, Hamid N, Avenatti E, Yao J, Hahn RT. Quantifying Tricuspid Regurgitation Severity: A Comparison of Proximal Isovelocity Surface Area and Novel Quantitative Doppler Methods. JACC Cardiovasc Imaging. 2019;12:560-2.

22. Muraru D, Previtero M, Ochoa-Jimenez RC, Guta AC, Figliozzi S, Gregori D, Bottigliengo D, Parati G, Badano LP. Prognostic validation of partition values for quantitative parameters to grade functional tricuspid regurgitation severity by conventional echocardiography. Eur Heart J Cardiovasc Imaging. 2021;22:155-65.

23. Peri Y, Sadeh B, Sherez C, Hochstadt A, Biner S, Aviram G, Ingbir M, Nachmany I, Topaz G, Flint N, Keren G, Topilsky Y. Quantitative assessment of effective regurgitant orifice: impact on risk stratification, and cut-off for severe and torrential tricuspid regurgitation grade. Eur Heart J Cardiovasc Imaging. 2020;21:768-76.

24. Santoro C, Marco Del Castillo A, Gonzalez-Gomez A, Monteagudo JM, Hinojar R, Lorente A, Abellas M, Vieitez JM, Garcia Martin A, Casas Rojo E, Ruiz S, Barrios V, Luis Moya J, Jimenez-Nacher JJ, Zamorano Gomez JL, Fernandez-Golfin C. Mid-term outcome of severe tricuspid regurgitation: are there any differences according to mechanism and severity? Eur Heart J Cardiovasc Imaging. 2019;20:1035-42.

25. Kebed KY, Addetia K, Henry M, Yamat M, Weinert L, Besser SA, Mor-Avi V, Lang RM. Refining Severe Tricuspid Regurgitation Definition by Echocardiography with a New Outcomes-Based "Massive" Grade. J Am Soc Echocardiogr. 2020;33: 1087-94

26. Fortuni F, Dietz MF, Prihadi EA, van der Bijl P, De Ferrari GM, Knuuti J, Bax JJ, Delgado V, Marsan NA. Prognostic Implications of a Novel Algorithm to Grade Secondary Tricuspid Regurgitation. JACC Cardiovasc Imaging. 2021;14:1085-95.

27. Hahn RT, Zamorano JL. The need for a new tricuspid regurgitation grading scheme. Eur Heart J Cardiovasc Imaging. 2017;18:1342-3.

28. Zhan Y, Debs D, Khan MA, Nguyen DT, Graviss EA, Khalaf S, Little SH, Reardon MJ, Nagueh S, Quinones MA, Kleiman N, Zoghbi WA, Shah DJ. Natura History of Functional Tricuspid Regurgitation Quantified by Cardiovascular Magnetic Resonance. J Am Coll Cardiol. 2020;76:1291-301.

29. Lang RM, Badano LP, Mor-Avi V, Afilalo J, Armstrong A, Ernande L, Flachskampf FA, Foster E, Goldstein SA, Kuznetsova T, Lancellotti P, Muraru D, Picard MH, Rietzschel ER, Rudski L, Spencer KT, Tsang W, Voigt JU. Recommendations for cardiac chamber quantification by echocardiography in adults: an update from the American Society of Echocardiography and the European Association of Cardiovascular Imaging. J Am Soc Echocardiogr. 2015;28:1-39.

30. Prihadi EA, van der Bijl P, Dietz M, Abou R, Vollema EM, Marsan NA, Delgado V, Bax JJ. Prognostic Implications of Right Ventricular Free Wall Longitudinal Strain in Patients With Significant Functional Tricuspid Regurgitation. Circ Cardiovasc Imaging. 2019;12:e08666.

31. Guazzi M, Dixon D, Labate V, Beussink-Nelson L, Bandera F, Cuttica MJ, Shah SJ RV Contractile Function and its Coupling to Pulmonary Circulation in Heart Failure With Preserved Ejection Fraction: Stratification of Clinical Phenotypes and Outcomes. JACC Cardiovasc Imaging. 2017;10:1211-21.

32. Tello K, Wan J, Dalmer A, Vanderpool R, Ghofrani HA, Naeije R, Roller F, Mohajerani E, Seeger W, Herberg U, Sommer N, Gall H, Richter MJ. Validation of the Tricuspid Annular Plane Systolic Excursion/Systolic Pulmonary Artery Pressure Ratio for the Assessment of Right Ventricular-Arterial Coupling in Severe Pulmonary Hypertension. Circ Cardiovasc Imaging. 2019;12:e009047.

33. Fortuni F, Butcher SC, Dietz MF, van der Bijl P, Prihadi EA, De Ferrari GM, Ajmone Marsan N, Bax JJ, Delgado V. Right Ventricular-Pulmonary Arterial Coupling in Secondary Tricuspid Regurgitation. Am J Cardiol. 2021;148:138-45.

34. Schlotter F, Miura M, Kresoja KP, Alushi B, Alessandrini H, Attinger-Toller A, Besler C, Biasco L, Braun D, Brochet E, Connelly KA, de Bruijn S, Denti P, EstevezLoureiro R, Fam N, Gavazzoni M, Himbert D, Ho EC, Juliard JM, Kalbacher D, Kaple R, Kreidel F, Latib A, Lubos E, Ludwig S, Mehr M, Monivas V, Nazif TM, Nickenig G, Pedrazzini G, Pozzoli A, Praz F, Puri R, Rodés-Cabau J, Rommel KP, Schäfer U, Schofer J, Sievert H, Tang GHL, Thiele H, Unterhuber M, Vahanian A, von Bardeleben RS, von Roeder M, Webb JG, Weber M, Wild MG, Windecker S, Zuber M, Hausleiter J, Maisano F, Leon MB, Hahn RT, Lauten A, Taramasso M, Lurz P. Outcomes of transcatheter tricuspid valve intervention by right ventricular function: a multicentre propensity-matched analysis. EuroIntervention. 2021;17:e343-52.

35. Grünig E, Tiede H, Enyimayew EO, Ehlken N, Seyfarth HJ, Bossone E, D'Andrea A, Naeije R, Olschewski H, Ulrich S, Nagel C, Halank M, Fischer C. Assessment and prognostic relevance of right ventricular contractile reserve in patients with severe pulmonary hypertension. Circulation. 2013;128:2005-15.

36. Harrison A, Hatton N, Ryan JJ. The right ventricle under pressure: evaluating the adaptive and maladaptive changes in the right ventricle in pulmonary arterial hypertension using echocardiography (2013 Grover Conference series). Pulm Circ. 2015; 5:29-47.
37. Grünig E, Weissmann S, Ehlken N, Fijalkowska A, Fischer C, Fourme T, Galie N, Ghofrani A, Harrison RE, Huez S, Humbert M, Janssen B, Kober J, Koehler R, Machado RD, Mereles D, Naeije R, Olschewski H, Provencher S, Reichenberger F, Retailleau K, Rocchi G, Simonneau G, Torbicki A, Trembath R, Seeger W. Stress Doppler echocardiography in relatives of patients with idiopathic and familial pulmonary arterial hypertension: results of a multicenter European analysis of pulmonary artery pressure response to exercise and hypoxia. Circulation. 2009;119:1747-57.

38. Tsukashita M, Takayama H, Takeda K, Han J, Colombo PC, Yuzefpolskaya M, Topkara VK, Garan AR, Mancini DM, Kurlansky PA, Naka Y. Effect of pulmonary vascular resistance before left ventricular assist device implantation on short- and longterm post-transplant survival. J Thorac Cardiovasc Surg. 2015;150:1352-60.

39. Kang G, Ha R, Banerjee D. Pulmonary artery pulsatility index predicts right ventricular failure after left ventricular assist device implantation. J Heart Lung Transplant. 2016;35:67-73

40. Lurz P, Orban M, Besler C, Braun D, Schlotter F, Noack T, Desch S, Karam N, Kresoja KP, Hagl C, Borger M, Nabauer M, Massberg S, Thiele H, Hausleiter J, Rommel KP. Clinical characteristics, diagnosis, and risk stratification of pulmonary hypertension in severe tricuspid regurgitation and implications for transcatheter tricuspid valve repair. Eur Heart J. 2020;41:2785-95.

41. Stirrat J, Rajchl M, Bergin L, Patton DJ, Peters T, White JA. High-resolution 3-dimensional late gadolinium enhancement scar imaging in surgically corrected Tetralogy of Fallot: clinical feasibility of volumetric quantification and visualization. J Cardiovasc Magn Reson. 2014;16:76.

42. Berg S, Torp H, Martens D, Steen E, Samstad S, Hoivik I, Olstad B. Dynamic three-dimensional freehand echocardiography using raw digital ultrasound data. Ultrasound Med Biol. 1999;25:745-53.

43. Lang RM, Singh A. Quantifying Right Ventricular Fibrosis Burden Using 3D Strain: Can Echo Approximate a Virtual Heart Biopsy? JACC Cardiovasc Imaging 2021;14:1321-3.

44. Enriquez-Sarano M, Messika-Zeitoun D, Topilsky Y, Tribouilloy C, Benfari G, Michelena H. Tricuspid regurgitation is a public health crisis. Prog Cardiovasc Dis. 2019;62:447-51.

45. Zack CJ, Fender EA, Chandrashekar P, Reddy YNV, Bennett CE, Stulak JM Miller VM, Nishimura RA. National Trends and Outcomes in Isolated Tricuspid Valve Surgery. J Am Coll Cardiol. 2017;70:2953-60

46. Dhoble A, Zhao Y, Vejpongsa P, Loghin C, Smalling RW, Estrera A, Nguyen TC. National 10-year trends and outcomes of isolated and concomitant tricuspid valve surgery. J Cardiovasc Surg (Torino). 2019;60:119-27.

47. Alqahtani F, Berzingi CO, Aljohani S, Hijazi M, Al-Hallak A, Alkhouli M Contemporary Trends in the Use and Outcomes of Surgical Treatment of Tricuspid Regurgitation. J Am Heart Assoc. 2017;6:e007597.

48. Dreyfus J, Flagiello M, Bazire B, Eggenspieler F, Viau F, Riant E, Mbaki Y, Bohbot Y, Eyharts D, Senage T, Dubrulle H, Nicol M, Doguet F, Nguyen V, Coisne A Le Tourneau T, Lavie-Badie Y, Tribouilloy C, Donal E, Tomasi J, Habib G, SeltonSuty C, Raffoul R, Iung B, Obadia JF, Messika-Zeitoun D. Isolated tricuspid valve surgery: impact of aetiology and clinical presentation on outcomes. Eur Heart J. 2020;41:4304-17.

49. Hamandi M, Smith RL, Ryan WH, Grayburn PA, Vasudevan A, George TJ, DiMaio JM, Hutcheson KA, Brinkman W, Szerlip M, Moore DO, Mack MJ. Outcomes of Isolated Tricuspid Valve Surgery Have Improved in the Modern Era. Ann Thorac Surg. 2019;108:11-5.

50. Kadri AN, Menon V, Sammour YM, Gajulapalli RD, Meenakshisundaram C, Nusairat L, Mohananey D, Hernandez AV, Navia J, Krishnaswamy A, Griffin B, Rodriguez L, Harb SC, Kapadia S. Outcomes of patients with severe tricuspid regurgitation and congestive heart failure. Heart. 2019;105:1813-7.

51. Park SJ, Gentry JL 3rd, Varma N, Wazni O, Tarakji KG, Mehta A, Mick S, Grimm R, Wilkoff BL. Transvenous Extraction of Pacemaker and Defibrillator Leads and the Risk of Tricuspid Valve Regurgitation. JACC Clin Electrophysiol. 2018; 4:1421-8.

52. Mehr M, Karam N, Taramasso M, Ouarrak T, Schneider S, Lurz P, von Bardeleben RS, Fam N, Pozzoli A, Lubos E, Boekstegers P, Schillinger W, Plicht B Eggebrecht H, Baldus S, Senges J, Maisano F, Hausleiter J; TriValve and TRAMI Investigators. Combined Tricuspid and Mitral Versus Isolated Mitral Valve Repair for Severe MR and TR: An Analysis From the TriValve and TRAMI Registries. JACC Cardiovasc Interv. 2020;13:543-50.

53. Kavsur R, Iliadis C, Spieker M, Brachtendorf BM, Tiyerili V, Metze C, Horn P, Baldus S, Kelm M, Nickenig G, Pfister R, Westenfeld R, Becher MU. Fate of Tricuspid Regurgitation in Patients Undergoing Transcatheter Edge-to-Edge Mitral Valve Repair. EuroIntervention. 2021 Mar 2. [Epub ahead of print]

54. Taramasso M, Benfari G, van der Bijl P, Alessandrini H, Attinger-Toller A, Biasco L, Lurz P, Braun D, Brochet E, Connelly KA, de Bruijn S, Denti P, Deuschl F, Estevez-Loureiro R, Fam N, Frerker C, Gavazzoni M, Hausleiter JR, Ho E, Juliard JM, 
Kaple R, Besler C, Kodali S, Kreidel F, Kuck KH, Latib A, Lauten A, Monivas V, Mehr M, Muntané-Carol G, Nazif T, Nickening G, Pedrazzini G, Philippon F, Pozzoli A, Praz F, Puri R, Rodés-Cabau J, Schäfer U, Schofer J, Sievert H, Tang GHL, Thiele H, Topilsky Y, Rommel KP, Delgado V, Vahanian A, Von Bardeleben RS, Webb JG, Weber M, Windecker S, Winkel M, Zuber M, Leon MB, Hahn RT, Bax JJ, Enriquez-Sarano M, Maisano F. Transcatheter Versus Medical Treatment of Patients With Symptomatic Severe Tricuspid Regurgitation. J Am Coll Cardiol. 2019;74: 2998-3008.

55. Vahanian A, Beyersdorf F, Praz F, Milojevic M, Baldus S, Bauersachs J, Capodanno D, Conradi L, De Bonis M, De Paulis R, Delgado V, Freemantle N, Gilard M, Haugaa KH, Jeppsson A, Jüni P, Pierard L, Prendergast BD, Sadaba JR, Tribouilloy C, Wojakowski W; ESC/EACTS Scientific Document Group. 2021 ESC/ EACTS Guidelines for the management of valvular heart disease. Eur Heart J. 2021 Aug 28. [Epub ahead of print].

56. Hammerstingl C, Schueler R, Malasa M, Werner N, Nickenig G. Transcatheter treatment of severe tricuspid regurgitation with the MitraClip system. Eur Heart $J$. 2016;37:849-53.

57. Braun D, Nabauer M, Massberg S, Hausleiter J. Transcatheter Repair of Primary Tricuspid Valve Regurgitation Using the MitraClip System. JACC Cardiovasc Interv. 2016;9:e153-4.

58. Nickenig G, Kowalski M, Hausleiter J, Braun D, Schofer J, Yzeiraj E, Rudolph V, Friedrichs K, Maisano F, Taramasso M, Fam N, Bianchi G, Bedogni F, Denti P, Alfieri O, Latib A, Colombo A, Hammerstingl C, Schueler R. Transcatheter Treatment of Severe Tricuspid Regurgitation With the Edge-to-Edge MitraClip Technique. Circulation. 2017;135:1802-14

59. Lurz P, Stephan von Bardeleben R, Weber M, Sitges M, Sorajja P, Hausleiter J, Denti P, Trochu JN, Nabauer M, Tang GHL, Biaggi P, Ying SW, Trusty PM, Dahou A, Hahn RT, Nickenig G; TRILUMINATE Investigators. Transcatheter Edge-to-Edge Repair for Treatment of Tricuspid Regurgitation. J Am Coll Cardiol. 2021;77:229-39. 60. Nickenig G, Weber M, Lurz P, von Bardeleben RS, Sitges M, Sorajja P, Hausleiter J, Denti P, Trochu JN, Näbauer M, Dahou A, Hahn RT. Transcatheter edge-to-edge repair for reduction of tricuspid regurgitation: 6-month outcomes of the TRILUMINATE single-arm study. Lancet. 2019;394:2002-11.

61. Orban M, Braun D, Deseive S, Stolz L, Stocker TJ, Stark K, Stremmel C, Orban M, Hagl C, Massberg S, Hahn RT, Nabauer M, Hausleiter J. Transcatheter Edge-to-Edge Repair for Tricuspid Regurgitation Is Associated With Right Ventricular Reverse Remodeling in Patients With Right-Sided Heart Failure. JACC Cardiovasc Imaging. 2019;12:559-60

62. Rommel KP, Besler C, Noack T, Blazek S, von Roeder M, Fengler K, Ender J, Gutberlet M, Desch S, Borger MA, Thiele H, Lurz P. Physiological and Clinical Consequences of Right Ventricular Volume Overload Reduction After Transcatheter Treatment for Tricuspid Regurgitation. JACC Cardiovasc Interv. 2019;12:1423-34.

63. Karam N, Braun D, Mehr M, Orban M, Stocker TJ, Deseive S, Orban M, Hagl C, Näbauer M, Massberg S, Hausleiter J. Impact of Transcatheter Tricuspid Valve Repair for Severe Tricuspid Regurgitation on Kidney and Liver Function. JACC Cardiovasc Interv. 2019;12:1413-20.

64. Taramasso M, Alessandrini H, Latib A, Asami M, Attinger-Toller A, Biasco L, Braun D, Brochet E, Connelly KA, Denti P, Deuschl F, Englmeier A, Fam N, Frerker C, Hausleiter J, Himbert D, Ho E, Juliard JM, Kaple R, Kreidel F, Kuck KH, Ancona M, Lauten A, Lurz P, Mehr M, Nazif T, Nickening G, Pedrazzini G, Pozzoli A, Praz F, Puri R, Rodés-Cabau J, Schäfer U, Schofer J, Sievert H, Sievert K, Tang GHL, Tanner FC, Vahanian A, Webb JG, Windecker S, Yzeiray E, Zuber M, Maisano F, Leon MB, Hahn RT. Outcomes After Current Transcatheter Tricuspid Valve Intervention: Mid-Term Results From the International TriValve Registry. JACC Cardiovasc Interv. 2019;12:155-65.

65. Ruf TF, Hahn RT, Kreidel F, Beiras-Fernandez A, Hell M, Gerdes P, da Roche E Silva JG, Vosseler M, Geyer M, Tamm A, Münzel T, von Bardeleben RS. Short-Term Clinical Outcomes of Transcatheter Tricuspid Valve Repair With the Third-Generation MitraClip XTR System. JACC Cardiovasc Interv. 2021;14:1231-40.

66. Kodali S, Hahn RT, Eleid MF, Kipperman R, Smith R, Lim DS, Gray WA, Narang A, Pislaru SV, Koulogiannis K, Grayburn P, Fowler D, Hawthorne K, Dahou A, Deo SH, Vandrangi P, Deuschl F, Mack MJ, Leon MB, Feldman T, Davidson CJ; CLASP TR EFS Investigators. Feasibility Study of the Transcatheter Valve Repair System for Severe Tricuspid Regurgitation. J Am Coll Cardiol. 2021;77:345-56.

67. Liu X, Pu Z, Lim DS, Wang J. Transcatheter mitral valve repair in a high-surgical risk patient with severe degenerative mitral regurgitation using the novel DragonFly ${ }^{\mathrm{TM}}$ Transcatheter Repair device-First in man implantation in China. Catheter Cardiovasc Interv. 2021 May 4. [Epub ahead of print].

68. Nickenig G, Weber M, Schueler R, Hausleiter J, Näbauer M, von Bardeleben RS, Sotiriou E, Schäfer U, Deuschl F, Kuck KH, Kreidel F, Juliard JM, Brochet E, Latib A, Agricola E, Baldus S, Friedrichs K, Vandrangi P, Verta P, Hahn RT, Maisano F. 6-Month Outcomes of Tricuspid Valve Reconstruction for Patients With Severe Tricuspid Regurgitation. J Am Coll Cardiol. 2019;73:1905-15.
69. Nickenig G, Weber M, Schüler R, Hausleiter J, Nabauer M, von Bardeleben RS, Sotiriou E, Schäfer U, Deuschl F, Alessandrini H, Kreidel F, Juliard JM, Brochet E, Latib A, Montorfano M, Agricola E, Baldus S, Friedrichs KP, Deo SH, Gilmore SY, Feldman T, Hahn RT, Maisano F. Tricuspid valve repair with the Cardioband system: two-year outcomes of the multicentre, prospective TRI-REPAIR study. EuroIntervention. 2021;16:e1264-71.

70. Nickenig G, Friedrichs KP, Baldus S, Arnold M, Seidler T, Hakmi S, Linke A, Schäfer U, Dreger H, Reinthaler M, von Bardeleben RS, Möllmann H, Weber M, Roder F, Körber MI, Landendinger M, Wolf F, Alessandrini H, Sveric K, Schewel D, RomeroDorta E, Kasner M, Dahou A, Hahn RT, Windecker S. Thirty-day outcomes of the Cardioband tricuspid system for patients with symptomatic functional tricuspid regurgitation: The TriBAND study. EuroIntervention. 2021 May 18. [Epub ahead of print].

71. Praz F, Brugger N. Transcatheter tricuspid valve treatment: does annular reduction make a difference? EuroIntervention. 2021;16:e1213-4.

72. Körber MI, Landendinger M, Gercek M, Beuthner BE, Friedrichs KP, Puls M, Baldus S, Rudolph V, Jacobshagen C, Arnold M, Pfister R. Transcatheter Treatment of Secondary Tricuspid Regurgitation With Direct Annuloplasty: Results From a Multicenter Real-World Experience. Circ Cardiovasc Interv. 2021:14:e010019.

73. Gercek M, Rudolph V, Arnold M, Beuthner BE, Pfister R, Landendinger M, Körber MI, Friedrichs KP, Jacobshagen C. Transient acute right coronary artery deformation during transcatheter interventional tricuspid repair with the Cardioband tricuspid system. EuroIntervention. 2021;17:81-7.

74. Rogers JH, Boyd WD, Bolling SF. Tricuspid annuloplasty with the Millipede ring. Prog Cardiovasc Dis. 2019;62:486-7.

75. Reddy VY, Abbo AR, Ruiz CE, Kerner A, Kreidel F, Topilsky Y, Kipshidze N, Avisar N, Petru J, Neuzil P. First-in-Human Percutaneous Circumferential Annuloplasty for Secondary Tricuspid Regurgitation. JACC Case Rep. 2020;2:2176-82.

76. Navia JL, Kapadia S, Elgharably H, Harb SC, Krishnaswamy A, Unai S, Mick S, Rodriguez L, Hammer D, Gillinov AM, Svensson LG. First-in-Human Implantations of the NaviGate Bioprosthesis in a Severely Dilated Tricuspid Annulus and in a Failed Tricuspid Annuloplasty Ring. Circ Cardiovasc Interv. 2017;10:e005840.

77. Hahn RT, George I, Kodali SK, Nazif T, Khalique OK, Akkoc D, Kantor A, Vahl TP, Patel A, Elias E, Ng V, Spina R, Bartus K, Velagapudi P, Wu I, Leon M, Bapat V. Early Single-Site Experience With Transcatheter Tricuspid Valve Replacement. JACC Cardiovasc Imaging. 2019;12:416-29.

78. Hahn RT, Kodali S, Fam N, Bapat V, Bartus K, Rodés-Cabau J, Dagenais F, Estevez-Loureiro R, Forteza A, Kapadia S, Latib A, Maisano F, McCarthy P, Navia J, Ong G, Peterson M, Petrossian G, Pozzoli A, Reinartz M, Ricciardi MJ, Robinson N, Sievert H, Taramasso M, Agarwal V, Bedard E, Tarantini G, Colli A. Early Multinational Experience of Transcatheter Tricuspid Valve Replacement for Treating Severe Tricuspid Regurgitation. JACC Cardiovasc Interv. 2020;13:2482-93.

79. Lu FL, An Z, Ma Y, Song ZG, Cai CL, Li BL, Zhou GW, Han L, Wang J, Bai YF, Liu XH, Wang JF, Meng X, Zhang HB, Yang J, Dong NG, Hu SS, Pan XB, Cheung A, Qiao F, Xu ZY. Transcatheter tricuspid valve replacement in patients with severe tricuspid regurgitation. Heart. 2021;107:1664-70.

80. Fam NP, von Bardeleben RS, Hensey M, Kodali SK, Smith RL, Hausleiter J, Ong G, Boone R, Ruf T, George I, Szerlip M, Näbauer M, Ali FM, Moss R, Bapat V, Schnitzler K, Kreidel F, Ye J, Deva DP, Mack MJ, Grayburn PA, Peterson MD, Leon MB, Hahn RT, Webb JG. Transfemoral Transcatheter Tricuspid Valve Replacement With the EVOQUE System: A Multicenter, Observational, First-inHuman Experience. JACC Cardiovasc Interv. 2021;14:501-11.

81. McElhinney DB, Cabalka AK, Aboulhosn JA, Eicken A, Boudjemline Y, Schubert S, Himbert D, Asnes JD, Salizzoni S, Bocks ML, Cheatham JP, Momenah TS, Kim DW, Schranz D, Meadows J, Thomson JD, Goldstein BH, Crittendon I 3rd, Fagan TE, Webb JG, Horlick E, Delaney JW, Jones TK, Shahanavaz S, Moretti C, Hainstock MR, Kenny DP, Berger F, Rihal CS, Dvir D; Valve-in-Valve International Database (VIVID) Registry. Transcatheter Tricuspid Valve-in-Valve Implantation for the Treatment of Dysfunctional Surgical Bioprosthetic Valves: An International, Multicenter Registry Study. Circulation. 2016;133:1582-93.

82. Bouleti C, Himbert D, Brochet E, Ou P, Iung B, Nejjari M, Ghodbane W, Fassa AA, Depoix JP, Vahanian A. Transfemoral tricuspid valve-in-ring implantation using the edwards Sapien XT valve: one-year follow-up. Circ Cardiovasc Interv. 2015;8:e002225. 83. Condado J, Leonardi R, Babaliaros V. Percutaneous tricuspid valve-In-ring replacement for the treatment of recurrent severe tricuspid regurgitation. Catheter Cardiovasc Interv. 2015;86:1294-8.

84. Dreger H, Mattig I, Hewing B, Knebel F, Lauten A, Lembcke A, Thoenes M, Roehle R, Stangl V, Landmesser U, Grubitzsch H, Stangl K, Laule M. Treatment of Severe TRIcuspid Regurgitation in Patients with Advanced Heart Failure with CAval Vein Implantation of the Edwards Sapien XT VALve (TRICAVAL): a randomised controlled trial. EuroIntervention. 2020;15:1506-13.

85. Dona C, Goliasch G, Schneider M, Hengstenberg C, Mascherbauer J. Transcatheter TricValve implantation for the treatment of severe tricuspid regurgitation. Eur Heart $J$ Cardiovasc Imaging. 2021;22:e92. 
86. Toggweiler S, De Boeck B, Brinkert M, Buhmann R, Bossard M, Kobza R, Cuculi F. First-in-man implantation of the Tricento transcatheter heart valve for the treatment of severe tricuspid regurgitation. EuroIntervention. 2018;14:758-61.

87. Montorfano M, Beneduce A, Ancona MB, Ancona F, Sgura F, Romano V, Ferri LA, Bellini B, Khawaja SA, Moroni F, Chieffo A, Carlino M, Agricola E. Tricento Transcatheter Heart Valve for Severe Tricuspid Regurgitation: Procedural Planning and Technical Aspects. JACC Cardiovasc Interv. 2019;12:e189-91.

88. Khalique OK, Cavalcante JL, Shah D, Guta AC, Zhan Y, Piazza N, Muraru D. Multimodality Imaging of the Tricuspid Valve and Right Heart Anatomy. JACC Cardiovasc Imaging. 2019;12:516-31.

89. Pighi M, Thériault-Lauzier P, Alosaimi H, Spaziano M, Martucci G, Xiong TY, Buithieu J, Ybarra LF, Afilalo J, Leipsic J, Ozden Tok O, Mousavi N, Mangiameli A, Pilgrim T, Praz F, Windecker S, Piazza N. Fluoroscopic Anatomy of Right-Sided Heart Structures for Transcatheter Interventions. JACC Cardiovasc Interv. 2018;11: 1614-25.

90. Robinson AA, Chadwell K, Fowler DE, Ailawadi G, Lim DS. Multiplane Intracardiac Echocardiography: A Novel System to Guide Percutaneous Tricuspid Repair. JACC Cardiovasc Interv. 2018;11:2540-2.

91. Alkhouli M, Hijazi ZM, Holmes DR Jr, Rihal CS, Wiegers SE. Intracardiac Echocardiography in Structural Heart Disease Interventions. JACC Cardiovasc Interv. 2018;11:2133-47.

92. Latib A, Mangieri A, Vicentini L, Ferri L, Montorfano M, Ismeno G, Regazzoli D, Ancona MB, Giglio M, Denti P, Colombo A, Agricola E. Percutaneous Tricuspid Valve Annuloplasty Under Conscious Sedation (With Only Fluoroscopic and Intracardiac Echocardiography Monitoring). JACC Cardiovasc Interv. 2017;10:620-1.

93. Tang GHL, Yakubov SJ, Sanchez Soto CE. 4-Dimensional Intracardiac Echocardiography in Transcatheter Tricuspid Valve Repair With the MitraClip System. JACC Cardiovasc Imaging. 2020;13:1591-600.

94. Chambers JB, Prendergast B, Iung B, Rosenhek R, Zamorano JL, Piérard LA, Modine T, Falk V, Kappetein AP, Pibarot P, Sundt T, Baumgartner H, Bax JJ, Lancellotti P. Standards defining a 'Heart Valve Centre': ESC Working Group on Valvular Heart Disease and European Association for Cardiothoracic Surgery Viewpoint. Eur Heart J. 2017;38:2177-83.

95. VARC-3 WRITING COMMITTEE: Généreux P, Piazza N, Alu MC, Nazif T, Hahn RT, Pibarot P, Bax JJ, Leipsic JA, Blanke P, Blackstone EH, Finn MT, Kapadia S, Linke A, Mack MJ, Makkar R, Mehran R, Popma JJ, Reardon M, Rodes-Cabau J, Van Mieghem NM, Webb JG, Cohen DJ, Leon MB. Valve Academic Research Consortium 3: Updated Endpoint Definitions for Aortic Valve Clinical Research. J Am Coll Cardiol. 2021;77:2717-46.

96. Stone GW, Adams DH, Abraham WT, Kappetein AP, Genereux P, Vranckx P, Mehran R, Kuck KH, Leon MB, Piazza N, Head SJ, Filippatos G, Vahanian AS; Mitral Valve Academic Research Consortium (MVARC). Clinical Trial Design Principles and Endpoint Definitions for Transcatheter Mitral Valve Repair and Replacement: Part 2: Endpoint Definitions: A Consensus Document From the Mitral Valve Academic Research Consortium. J Am Coll Cardiol. 2015;66:308-21.

97. Smuck M, Odonkor CA, Wilt JK, Schmidt N, Swiernik MA. The emerging clinical role of wearables: factors for successful implementation in healthcare. NPJ Digit Med. 2021;4:45.

98. Stocker TJ, Scheck F, Orban M, Braun D, Hertell H, Lackermair K, Deseive S, Mehr M, Orban M, Karam N, Nabauer M, Massberg S, Hausleiter J. Physical activity tracking in correlation to conventional heart failure monitoring assessing improvements after transcatheter mitral and tricuspid valve repair. Eur J Heart Fail. 2019; 21:943-5.

99. Stocker TJ, Orban M, Braun D, Scheck F, Weckbach LT, Orban M, Deseive S, Nabauer M, Massberg S, Hausleiter J. Physical Activity and Noninvasive Cardiac Output as Novel Clinical Endpoints After Transcatheter Valve Repair for Severe Tricuspid Regurgitation. JACC Cardiovasc Interv. 2018;11:2127-9.

100. Lander MM, Aldweib N, Abraham WT. Wireless Hemodynamic Monitoring in Patients with Heart Failure. Curr Heart Fail Rep. 2021;18:12-22.

101. Guta AC, Badano LP, Tomaselli M, Mihalcea D, Bartos D, Parati G, Muraru D. The Pathophysiological Link between Right Atrial Remodeling and Functional Tricus- pid Regurgitation in Patients with Atrial Fibrillation: A Three-Dimensional Echocardiography Study. J Am Soc Echocardiogr. 2021;34:585-94.

102. Topilsky Y, Khanna A, Le Tourneau T, Park S, Michelena H, Suri R, Mahoney DW, Enriquez-Sarano M. Clinical context and mechanism of functional tricuspid regurgitation in patients with and without pulmonary hypertension. Circ Cardiovasc Imaging. 2012;5:314-23

103. Seko Y, Kato T, Shiba M, Morita Y, Yamaji Y, Haruna Y, Nakane E, Haruna T, Inoko M. Isolated Tricuspid Regurgitation and Long-Term Outcome in Patients With Preserved Ejection Fraction. Circ Rep. 2019;1:617-22.

104. Mascherbauer J, Kammerlander AA, Zotter-Tufaro C, Aschauer S, Duca F, Dalos D, Winkler S, Schneider M, Bergler-Klein J, Bonderman D. Presence of 'isolated' tricuspid regurgitation should prompt the suspicion of heart failure with preserved ejection fraction. PLoS One. 2017;12:e0171542.

105. Addetia K, Maffessanti F, Mediratta A, Yamat M, Weinert L, Moss JD, Nayak HM, Burke MC, Patel AR, Kruse E, Jeevanandam V, Mor-Avi V, Lang RM. Impact of implantable transvenous device lead location on severity of tricuspid regurgitation. $J$ Am Soc Echocardiogr. 2014;27:1164-75.

106. Mediratta A, Addetia K, Yamat M, Moss JD, Nayak HM, Burke MC, Weinert L, Maffessanti F, Jeevanandam V, Mor-Avi V, Lang RM. 3D echocardiographic location of implantable device leads and mechanism of associated tricuspid regurgitation. JACC Cardiovasc Imaging. 2014;7:337-47.

107. Henry M, Abutaleb A, Jeevanandam V, Smith H, Belkin M, Husain A, Pinney S, Ota T, Lang RM, Addetia K. Anatomic Description of Tricuspid Apparatus Interference From Implantable Intracardiac Devices. JACC Cardiovasc Imaging. 2021 Feb 2. [Epub ahead of print].

108. Addetia K, Harb SC, Hahn RT, Kapadia S, Lang RM. Cardiac Implantable Electronic Device Lead-Induced Tricuspid Regurgitation. JACC Cardiovasc Imaging. 2019;12:622-36.

109. Bhattacharyya S, Toumpanakis C, Burke M, Taylor AM, Caplin ME, Davar J. Features of carcinoid heart disease identified by 2- and 3-dimensional echocardiography and cardiac MRI. Circ Cardiovasc Imaging. 2010;3:103-11.

110. Utsunomiya H, Itabashi Y, Mihara H, Kobayashi S, De Robertis MA, Trento A, Shiota T. Usefulness of 3D echocardiographic parameters of tricuspid valve morphology to predict residual tricuspid regurgitation after tricuspid annuloplasty. Eur Heart $J$ Cardiovasc Imaging. 2017;18:809-17.

111. Fukuda S, Song JM, Gillinov AM, McCarthy PM, Daimon M, Kongsaerepong V, Thomas JD, Shiota T. Tricuspid valve tethering predicts residual tricuspid regurgitation after tricuspid annuloplasty. Circulation. 2005;111:975-9.

\section{Supplementary data}

Supplementary Table 1. Proposed expansion of the "severe" grade of TR.

Supplementary Table 2. Echocardiographic measures of RV size and function.

Supplementary Table 3. Specific tricuspid regurgitation aetiologies and specialised care.

Supplementary Figure 1. Steps to identifying tricuspid valve leaflets.

Supplementary Figure 2. Assessment of TR severity by Doppler echocardiography.

Supplementary Figure 3. Imaging and interventional perspectives of the tricuspid valve.

The supplementary data are published online at:

https://eurointervention.pcronline.com/

doi/10.4244/EIJ-D-21-00695 


\section{Supplementary data}

Supplementary Table 1. Proposed expansion of the "severe" grade of TR.

\begin{tabular}{lccccc}
\hline Variable & Mild & Moderate & Severe & Massive & Torrential \\
& & & & & \\
\hline VC (biplane) & $<3 \mathrm{~mm}$ & $3-6.9 \mathrm{~mm}$ & $7-13 \mathrm{~mm}$ & $14-20 \mathrm{~mm}$ & $\geq 21 \mathrm{~mm}$ \\
EROA (PISA) & $<20 \mathrm{~mm}^{2}$ & $20-39 \mathrm{~mm}^{2}$ & $40-59 \mathrm{~mm}^{2}$ & $60-79 \mathrm{~mm}^{2}$ & $\geq 80 \mathrm{~mm}^{2}$ \\
3D VCA or quantitative EROA* & & & $75-94$ & $95-114 \mathrm{~mm}^{2}$ & $\geq 115 \mathrm{~mm}^{2}$ \\
& & & & & \\
\hline
\end{tabular}

* 3D VCA and quantitative Doppler EROA cut-offs may be larger than PISA EROA.

EROA: effective regurgitant orifice area; PISA: proximal isovelocity surface area; VC: vena contracta; 3D VCA, three-dimensional vena contracta area 
Supplementary Table 2. Echocardiographic measures of RV size and function.

\begin{tabular}{|c|c|c|}
\hline RV size parameter & Mean \pm SD & Normal range \\
\hline RV basal diameter, $\mathrm{mm}$ & $33 \pm 4$ & $25-41$ \\
\hline $\mathrm{RV}$ mid diameter, $\mathrm{mm}$ & $27 \pm 4$ & $19-35$ \\
\hline $\mathrm{RV}$ longitudinal diameter, $\mathrm{mm}$ & $71 \pm 6$ & $59-83$ \\
\hline RVOT PLAX diameter, mm & $25 \pm 2.5$ & $20-30$ \\
\hline RVOT proximal diameter, $\mathrm{mm}$ & $28 \pm 3.5$ & $21-35$ \\
\hline RVOT distal diameter, $\mathrm{mm}$ & $22 \pm 2.5$ & $17-27$ \\
\hline $\begin{array}{l}\text { RV EDV, } \mathrm{mL} / \mathrm{m}^{2} \\
\text { Men } \\
\text { Women }\end{array}$ & $\begin{array}{l}61 \pm 13 \\
53 \pm 10.5\end{array}$ & $\begin{array}{l}35-87 \\
32-74\end{array}$ \\
\hline $\begin{array}{l}\text { RV ESV, } \mathrm{mL} / \mathrm{m}^{2} \\
\text { Men } \\
\text { Women }\end{array}$ & $\begin{array}{l}27 \pm 8.5 \\
22 \pm 7\end{array}$ & $\begin{array}{l}10-44 \\
8-36\end{array}$ \\
\hline $\mathrm{RV}$ wall thickness, $\mathrm{mm}$ & 31 & $1-5$ \\
\hline RV function parameter & Normal range & Abnormal \\
\hline TAPSE, mm & $24 \pm 3.5$ & $<17$ \\
\hline DTI S', cm/s & $14.1 \pm 2.3$ & $<9.5$ \\
\hline Free wall LS, \% & $-29 \pm 4.5$ & $>-20$ \\
\hline RIMP (PW Doppler) & $0.25 \pm 0.085$ & $>0.43$ \\
\hline RIMP (DTI) & $0.38 \pm 0.08$ & $>0.54$ \\
\hline FAC, $\%$ & $49 \pm 7$ & $<35$ \\
\hline RVEF, \% & $58 \pm 6.5$ & $<45$ \\
\hline
\end{tabular}

DTI: Doppler tissue imaging; EDV: end-diastolic volume; ESV: end-systolic volume; FAC: fractional area change; LS: longitudinal strain; PLAX: parasternal long-axis view; PW: pulsed-wave; RIMP: right ventricular index of myocardial performance; RV: right ventricular; RVEF: right ventricular ejection fraction; RVOT: right ventricular outflow tract; SD: standard deviation; TAPSE: tricuspid annular plane systolic excursion 
Supplementary Table 3. Specific tricuspid regurgitation aetiologies and specialised care.

\begin{tabular}{|c|c|c|c|c|c|c|c|}
\hline Phenotype & Mechanism of TR & $\begin{array}{l}\text { Annular } \\
\text { dilation }\end{array}$ & $\begin{array}{l}\text { Leaflet } \\
\text { tenting }\end{array}$ & $\begin{array}{l}\text { Leaflet } \\
\text { disease }\end{array}$ & Referral specialist & $\begin{array}{l}\text { Diagnostic } \\
\text { workup }\end{array}$ & $\begin{array}{l}\text { Percutaneous } \\
\text { treatment }\end{array}$ \\
\hline $\begin{array}{l}\text { Atrial } \\
\text { fibrillation }\end{array}$ & Biatrial disease & +++ & $+/ \pm$ & $-/+$ & Electrophysiologist & $\begin{array}{l}\text { Imaging*, } \\
\text { RHC }\end{array}$ & Possible \\
\hline Left-sided HF & $\begin{array}{l}\text { Progression of cardiac } \\
\text { dysfunction }\end{array}$ & ++ & ++ & - & Heart failure specialist & $\begin{array}{l}\text { Imaging^, } \\
\text { RHC }\end{array}$ & Possible \\
\hline $\begin{array}{l}\text { Left-sided valve } \\
\text { disease }\end{array}$ & $\begin{array}{l}\text { Primary valve } \\
\text { disease/post-capillary } \\
\text { pulmonary hypertension }\end{array}$ & ++ & ++ & + & $\begin{array}{l}\text { Interventional cardiologist/ cardiac } \\
\text { surgeon /echocardiographer }\end{array}$ & $\begin{array}{l}\text { Imaging^, } \\
\text { RHC }\end{array}$ & Possible \\
\hline $\begin{array}{l}\text { Pulmonary } \\
\text { hypertension }\end{array}$ & $\begin{array}{l}\text { Right ventricular } \\
\text { dysfunction/remodelling }\end{array}$ & ++ & +++ & $-/ \pm$ & $\begin{array}{l}\text { Pulmonary hypertension centre } \\
\text { Heart failure } \\
\text { specialist/pneumologists/rheumatologist }\end{array}$ & $\begin{array}{l}\text { Imaging, } \\
\text { RHC }\end{array}$ & Unlikely \\
\hline $\begin{array}{l}\mathrm{RV} \\
\text { cardiomyopathy }\end{array}$ & $\begin{array}{l}\text { Right ventricular } \\
\text { dysfunction/remodelling }\end{array}$ & ++ & ++ & - & Heart failure specialist & $\begin{array}{l}\text { Imaging, } \\
\text { RHC }\end{array}$ & Possible \\
\hline CIED related & Mechanical interference & \pm & - & $\pm \S$ & Electrophysiologist & $\begin{array}{l}\text { Imaging, } \\
\text { RHC }\end{array}$ & $\begin{array}{l}\text { Sometimes } \\
\text { possible }\end{array}$ \\
\hline Primary TR & $\begin{array}{l}\text { Tricuspid apparatus } \\
\text { disease }\end{array}$ & + & - & +++ & $\begin{array}{l}\text { Cardiac surgeon/interventional } \\
\text { cardiologist/echocardiographer }\end{array}$ & $\begin{array}{l}\text { Imaging, } \\
\text { RHC }\end{array}$ & $\begin{array}{l}\text { Sometimes } \\
\text { possible }\end{array}$ \\
\hline
\end{tabular}

* 2D, 3D and Doppler echocardiography; CCT

^ 2D, 3D and Doppler echocardiography; CCT and CMR in controversial cases

$\S$ Depending on the mechanism (i.e., impinging vs entanglement vs perforation, etc.)

CIED: cardiac implantable electronic device; HF: heart failure; RHC: right heart catheterisation; RV: right ventricle; TR: tricuspid regurgitation 


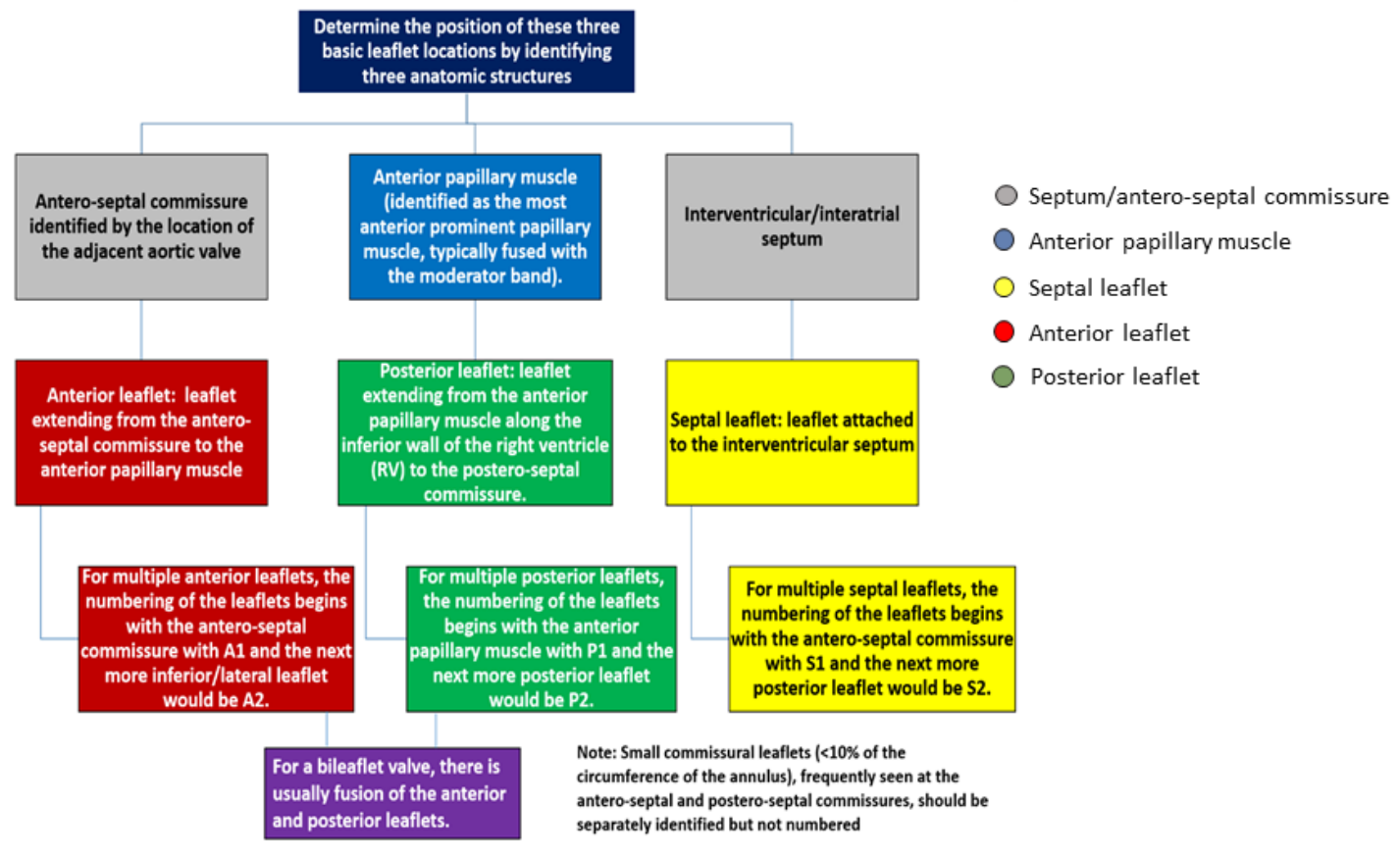

Supplementary Figure 1. Steps to identifying tricuspid valve leaflets.

Deep indentations and true commissures are considered anatomically equivalent and are used to identify supernumerary leaflets. A separate leaflet is defined by: (1) independent motion from the adjacent leaflet, and (2) colour Doppler systolic flow extending into the region around the leaflet. Four major classes of leaflet morphologies are possible. Colour-coding corresponds to Figure 1. 


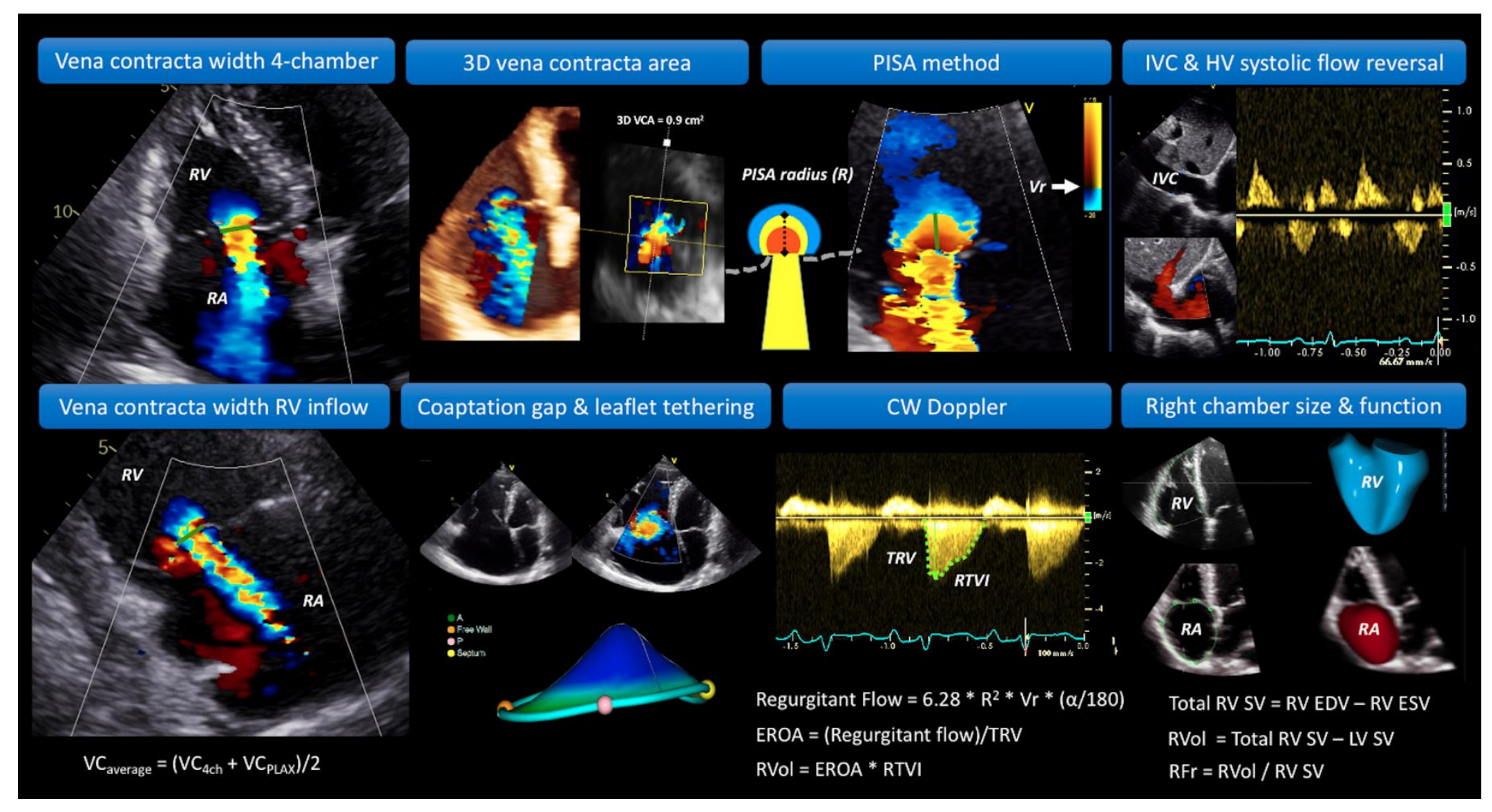

Supplementary Figure 2. Assessment of TR severity by Doppler echocardiography.

4ch: 4-chamber; EDV: end-diastolic volume; EROA: effective regurgitant orifice area; ESV: end-systolic volume; HV: hepatic vein; IVC: inferior vena cava; LV: left ventricular; PISA: proximal isolvelocity surface area; PLAX: parasternal long-axis; R: radius; RA: right atrium; RTVI: velocitytime integral of regurgitant jet; RV: right ventricle; SV: stroke volume; TRV: peak velocity TR jet; VC: vena contracta; VCA: vena contracta area; Vr: aliasing velocity 
A
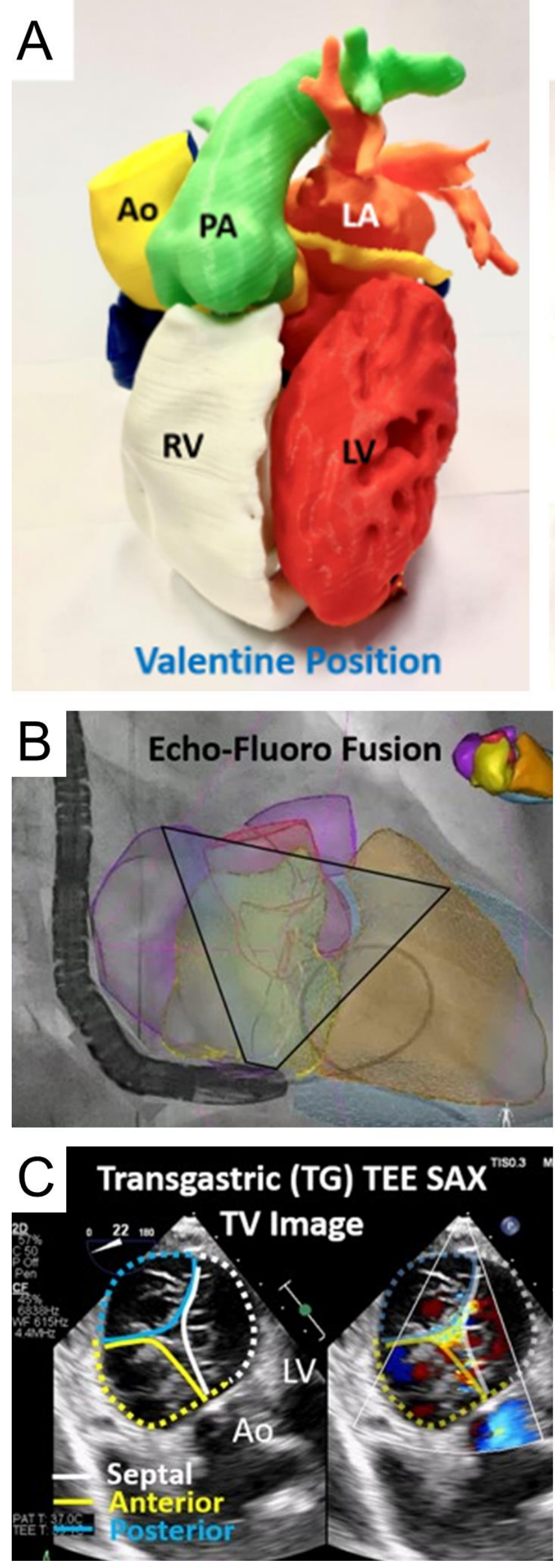

D

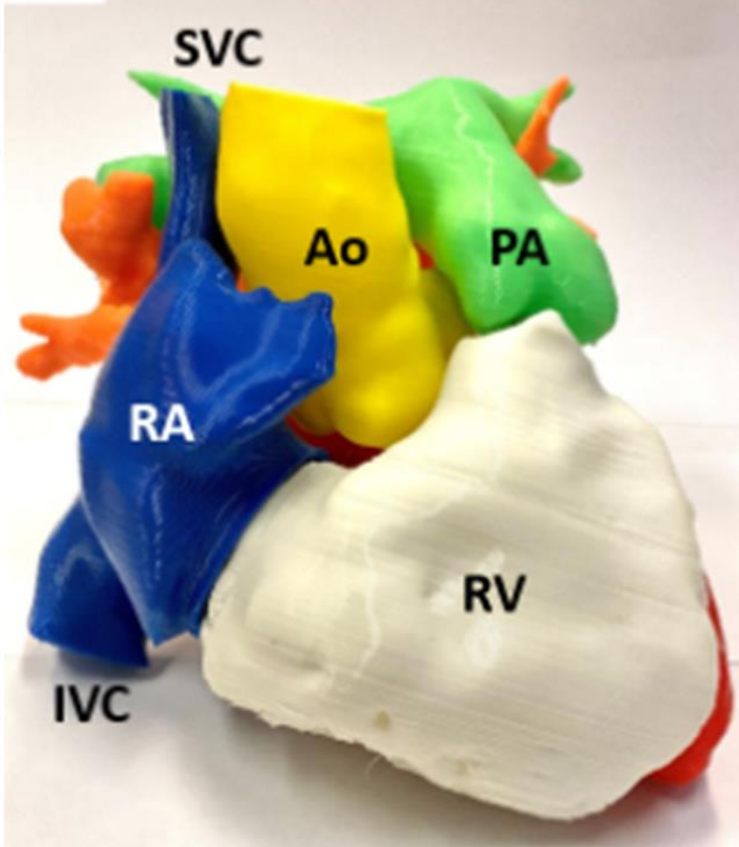

Attitudinal Position

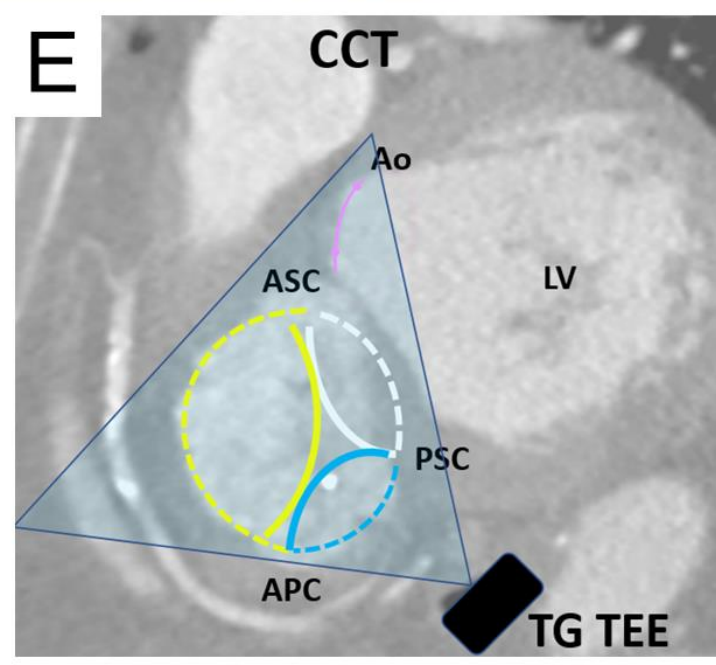

$\mathrm{F}$ Fluoroscopy

Ao

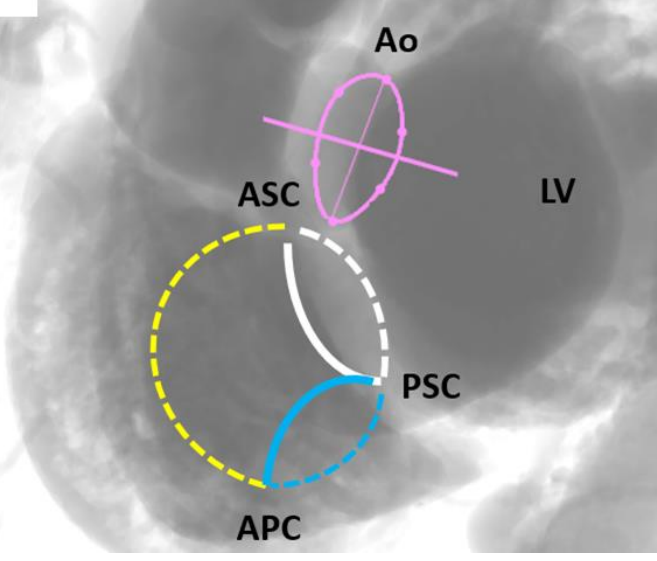


Supplementary Figure 3. Imaging and interventional perspectives of the tricuspid valve.

A) The traditional way to display the heart ("Valentine"), according to which the nomenclature of its structures derives from viewing the heart in an anterior orientation with the apex down.

B \& C) Conventional nomenclature of the tricuspid leaflets (septal, anterior, posterior) applies for the conventional "Valentine" position and for transoesophageal echocardiographic (TEE) imaging when the probe is behind the heart.

D) Attitudinal position of the heart seen from the front as it lies on the diaphragm within the thorax, where the "right" chambers are anterior with respect to "left" chambers, the latter not being visible from this view.

$\mathrm{E} \& \mathrm{~F}$ ) According to attitudinal position, the nomenclature of the leaflets is: posterior (for septal), antero-superior (for anterior) and inferior (for posterior), according to their spatial position within the body, as depicted by CT (E) and fluoro images (F).

A: anterior; Ao: aorta; APC: anteroposterior commissure; ASC: anteroseptal commissure; CCT: cardiac computed tomography; IVC: inferior vena cava; LA: left atrium; LV: left ventricle; P: posterior; PA: pulmonary artery; PSC: posteroseptal commissure; RA: right atrium; RV: right ventricle; S: septal; SAX: short axis; SVC: superior vena cava; TEE: transoesophageal echocardiography; TG: transgastric; TV: tricuspid valve 